ARTICLE

Received 28 Nov 2014 | Accepted 30 Jun 2015 | Published 21 Aug $2015 \quad$ DOl: 10.1038/ncomms8938

\title{
Catalysis on singly dispersed bimetallic sites
}

\author{
Shiran Zhang ${ }^{1,2, \star}$, Luan Nguyen ${ }^{1,2, \star}$, Jin-Xia Liang ${ }^{3,4, \star}$, Junjun Shan ${ }^{1,2}$, Jingyue (Jimmy) Liu ${ }^{5}$, \\ Anatoly I. Frenkel ${ }^{6}$, Anitha Patlolla ${ }^{6}$, Weixin Huang ${ }^{1,2}$, Jun $\mathrm{Li}^{3} \&$ Franklin (Feng) Tao ${ }^{1,2}$
}

A catalytic site typically consists of one or more atoms of a catalyst surface that arrange into a configuration offering a specific electronic structure for adsorbing or dissociating reactant molecules. The catalytic activity of adjacent bimetallic sites of metallic nanoparticles has been studied previously. An isolated bimetallic site supported on a non-metallic surface could exhibit a distinctly different catalytic performance owing to the cationic state of the singly dispersed bimetallic site and the minimized choices of binding configurations of a reactant molecule compared with continuously packed bimetallic sites. Here we report that isolated $\mathrm{Rh}_{1} \mathrm{Co}_{3}$ bimetallic sites exhibit a distinctly different catalytic performance in reduction of nitric oxide with carbon monoxide at low temperature, resulting from strong adsorption of two nitric oxide molecules and a nitrous oxide intermediate on $\mathrm{Rh}_{1} \mathrm{Co}_{3}$ sites and following a low-barrier pathway dissociation to dinitrogen and an oxygen atom. This observation suggests a method to develop catalysts with high selectivity.

\footnotetext{
${ }^{1}$ Department of Chemical and Petroleum Engineering, University of Kansas, Lawrence, Kansas 66047, USA. ${ }^{2}$ Department of Chemistry, University of Kansas, Lawrence, Kansas 66047, USA. ${ }^{3}$ Department of Chemistry and Key Laboratory of Organic Optoelectronics and Molecular Engineering of Ministry of Education, Tsinghua University, Beijing 100084, China. ${ }^{4}$ Guizhou Provincial Key Laboratory of Computational Nano-Material Science, Guizhou Normal College, Guiyang 550018, China. ${ }^{5}$ Department of Physics, Arizona State University, Tempe, Arizona 85287, USA. ${ }^{6}$ Department of Physics, Yeshiva University, New York, New York 10016, USA. * These authors contributed equally to this work. Correspondence and requests for materials should be addressed to J.L. (email: junli@tsinghua.edu.cn) or to F.T. (email: franklin.feng.tao@ku.edu).
} 
single reaction event of heterogeneous catalysis occurs on a specific catalytic site at atomic or nanoscale ${ }^{1-3}$. An active catalytic site catalyses a reaction by decreasing its activation barrier through a reaction pathway different from that without a catalyst. Typically, a catalytic site may consist of one, two or a few atoms of surface of a catalyst particle. Atoms of a catalytic site arrange into a configuration that essentially offers a specific electronic structure for the catalytic cycle. Bimetallic nanoparticle catalysts play significant roles in chemical and energy transformations since the second metal (A) could tune catalytic performance of a monometallic catalyst (M) through ligand effect, geometric effect, bi-functional effect or lattice strain effect ${ }^{2-5}$ (Fig. 1a,b). Atoms of a catalytic site of a bimetallic nanoparticle could come from more than one element (for example, $\mathrm{M}$ and A in Fig. 1c). Alternatively, they could come from the same element (for example, $M$ in Fig. 1d) though surface of the bimetallic nanoparticles has both elements $\mathrm{M}$ and $\mathrm{A}$. In the latter case, atoms of element $\mathrm{A}$ are the modifier of electronic structure but do not directly participate into the catalysis. When metal atoms of a catalytic site come from two different metal a

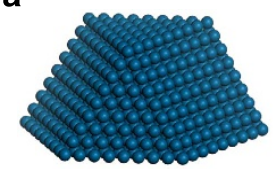

Mono-metallic nanoparticle b

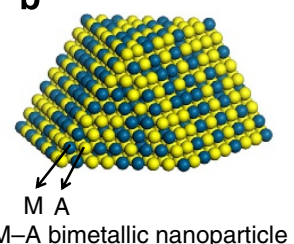

A catalytic reaction on a bimetallic catalyst (M-A) $\mathrm{R}_{1}+\mathrm{R}_{2} \rightarrow$ products
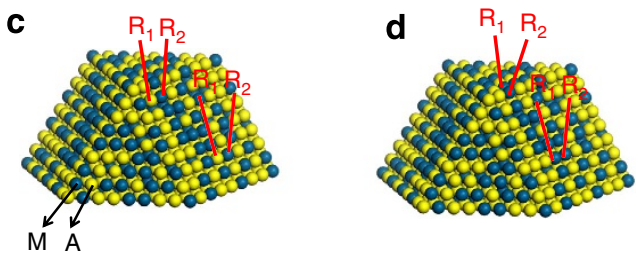

Isolate continuously packed bimetallic sites

e

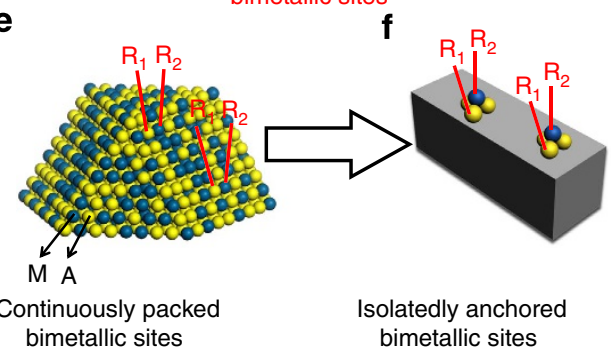

Figure 1 | Schematic illustration of the isolation of continuous bimetallic sites of alloy nanoparticle to SBMS. Blue and yellow balls represent atoms of metal elements $M$ and $A . R_{1}$ and $R_{2}$ are different reactants. (a) Schematic of a monometallic nanoparticle. (b) Schematic of a bimetallic nanoparticle. (c) Surface of an M-A bimetallic nanoparticle consisting of continuous bimetallic sites; $R_{1}$ and $R_{2}$ bind to $A$ and $M$ atoms, respectively. (d) Surface of an $\mathrm{M}-\mathrm{A}$ bimetallic nanoparticle consisting of continuous bimetallic sites; however, $R_{1}$ and $R_{2}$ only bind to atoms of metal $M$ instead of $A ; A$ is only the modifier of electronic or/and geometric structure. (e) Surface of an M-A bimetallic nanoparticle consisting of continuous bimetallic sites. (f) Isolated bimetallic sites anchored on a non-metallic support; different from the multiple binding configurations of $R_{2}$ on an $\mathrm{M}-\mathrm{A}$ bimetallic nanoparticle, here $R_{2}$ can only bind to the single atom $M$ through an on-top binding configuration. elements such as $\mathrm{M}$ and A, we term it a 'bimetallic' site (Fig. 1c); in this case, atoms from both $\mathrm{M}$ and $\mathrm{A}$ directly participate into the catalytic reaction. One type of such bimetallic sites is referred to $\mathrm{M}_{1} \mathrm{~A}_{n}$ (M and $\mathrm{A}$ : metal elements, $n \geq 1$ ), in which both $\mathrm{M}$ and A directly participate into a catalytic reaction. The feature of such a bimetallic site is that there is only one atom of $M$ though there is one or more atoms of $\mathrm{A}$.

Typically, such a bimetallic site, $\mathrm{M}_{1} \mathrm{~A}_{n}$ is continuously packed on surface of a bimetallic nanoparticle. Thus, the $\mathrm{M}_{1} \mathrm{~A}_{n}$ sites on surface of a bimetallic nanoparticle are at a metallic state. However, if such bimetallic sites $\left(\mathrm{M}_{1} \mathrm{~A}_{n}\right)$ are separately anchored on the surface of a non-metallic support such as a transition metal oxide, these isolated bimetallic sites (Fig. 1f) are at cationic state. Such isolated bimetallic sites could provide a different surface process including adsorption and dissociation for a reactant molecule or/and an intermediate compared with continuously packed bimetallic sites on a bimetallic nanoparticle. Such a different surface process could facilitate dissociation of a reactant molecule and then accelerate a subsequent coupling with another reactant molecule/dissociated species to form an intermediate or a product molecule. In addition, the single dispersion of atom $M$ of an isolated bimetallic site $\left(M_{1} A_{n}\right)$ minimizes choices of potential binding configurations of a reactant molecule, dissociated species, or intermediate on catalyst surface (Fig. 1f), in contrast to the potential multiple choices of binding configurations such as on-top, bridge or hollow sites on the surface of a bimetallic nanoparticle. For example, on an $\mathrm{M}-\mathrm{A}$ bimetallic nanoparticle surface, a $\mathrm{R}_{2}$ molecule could bind to atop, bridge or even hollow site of $\mathrm{M}$ atoms. However, $\mathrm{R}_{2}$ can bind to $\mathrm{M}$ atom through only an atop binding (Fig. 1f) on an isolated bimetallic site $M_{1} A_{n}$. Consequently, the minimized choices of binding configurations of reactant, dissociated species or intermediate on isolated $\mathrm{M}_{1} \mathrm{~A}_{n}$ sites may enhance catalytic selectivity by following a specific reaction pathway if there are multiple pathways on a bimetallic nanoparticle.

Here we report the preparation of a catalyst consisting of singly dispersed bimetallic sites (SBMS) $\mathrm{Rh}_{1} \mathrm{Co}_{3}$ through controlled oxidation and reduction processes with the aid of in situ track of evolution of chemistry and structure of the catalyst precursor, and the unique catalytic performance of $\mathrm{Rh}_{1} \mathrm{Co}_{3}$ in terms of $100 \%$ selectivity for reducing $\mathrm{NO}$ to $\mathrm{N}_{2}$ at $110^{\circ} \mathrm{C}$ with a much higher activity than $\mathrm{Rh}-\mathrm{Co}$ bimetallic nanoparticles at this temperature. Our results illustrate that isolation of bimetallic sites of bimetallic nanoparticles could be used to develop catalysts with higher selectivity or activity.

\section{Results}

Synthesis of a catalyst of isolated bimetallic sites $\mathrm{Rh}_{1} \mathrm{Co}_{3}$. As shown in Fig. 2, the synthesis of a catalyst of isolated bimetallic sites begins with the formation of hydroxide species $\mathrm{M}(\mathrm{OH})_{z}$ on the surface of a reducible oxide $\mathrm{A}_{x} \mathrm{O}_{y}$, followed by a calcination at $150{ }^{\circ} \mathrm{C}$ in $\mathrm{O}_{2}$ to anchor $\mathrm{M}$ to the surface through formation of $\mathrm{M}-\mathrm{O}-\mathrm{A}$ bonds between singly dispersed $\mathrm{M}(\mathrm{OH})_{z}$ species and the surface of the support $\mathrm{A}_{x} \mathrm{O}_{y}$, and concluded with a controlled reduction at $300{ }^{\circ} \mathrm{C}$ in $5 \% \mathrm{H}_{2}$ to remove some of the oxygen atoms bonded to both atom $\mathrm{M}_{1}$ and atoms $\mathrm{A}$ of the surface, thus forming $\mathrm{M}-\mathrm{A}$ bonds on the surface of the oxide (Fig. 2).

An over-reduction of the support $\mathrm{A}_{x} \mathrm{O}_{y}$ typically forms an ultrathin bimetallic film of metals $\mathrm{M}$ and $\mathrm{A}$; in this case, the guest metal atoms $\mathrm{M}$ may alloy with metal atoms of $\mathrm{A}$ to form a bimetallic thin layers (Supplementary Fig. 1) instead of isolated $\mathrm{M}_{1} \mathrm{~A}_{n}$ bimetallic sites. On the other hand, a less reduction in terms of a reduction at a relatively low temperature could not remove oxygen atoms between $\mathrm{M}_{1}$ and $\mathrm{A}$ of $\mathrm{M}_{1} \mathrm{O}_{n} / \mathrm{A}_{x} \mathrm{O}_{y}$; in this 
a

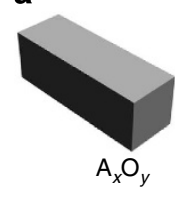

b

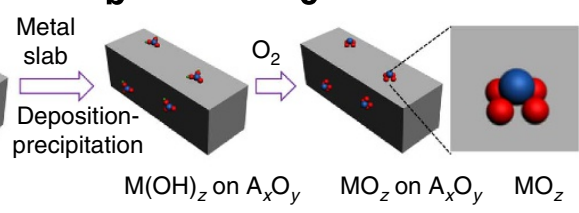

d

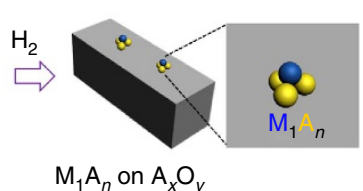

\section{$\mathrm{OM} \mathrm{OO} \bullet \mathrm{H} O \mathrm{~A} \gg \mathrm{A}_{x} \mathrm{O}_{y}$}

Figure 2 | Schematic of synthesis of a catalyst of singly dispersed bimetallic sites $\mathbf{M}_{\mathbf{1}} \mathbf{A}_{\boldsymbol{n}}$ ( (a) Well-crystallized reducible oxide substrate, $A_{x} \mathrm{O}_{y}$. (b) Deposition of hydroxide species of guest metal, $\mathrm{M}(\mathrm{OH})_{z}$, to surface of the oxide support, $\mathrm{A}_{x} \mathrm{O}_{y}$; a low concentration of $\mathrm{M}$ cations $(0.5$ wt\% or less) allows them to be singly dispersed on the surface of $A_{x} \mathrm{O}_{y}$; the atomic ratio of $M$ atoms to $A$ atoms of the topmost layer of atoms $A$ of $A_{x} O_{y}$ is typically $<5-10 \% ; \mathrm{M}(\mathrm{OH})_{z}$ species are weakly bound to the surface of $\mathrm{A}_{x} \mathrm{O}_{y}$. (c) Formation of singly dispersed $\mathrm{M}_{1} \mathrm{O}_{n}$ species upon oxidation in $5 \% \mathrm{O}_{2}$ at $150{ }^{\circ} \mathrm{C}$; $\mathrm{M}$ cations are bonded to $\mathrm{A}_{x} \mathrm{O}_{y}$ surface through $\mathrm{M}-\mathrm{O}-\mathrm{A}$ bonds. (d) $\mathrm{A}$ controlled reduction in $5 \% \mathrm{H}_{2}$; removal of oxygen atoms between $\mathrm{M}$ and $\mathrm{A}$ atoms by reduction in $\mathrm{H}_{2}$ makes $M$ directly bond with $A$ atoms of oxide support, forming an $M_{1} A_{n}$ site; as $M$ atoms are singly dispersed on $A_{x} O_{y}$ (due to the low concentration of guest atoms $M$ ), the formed $M_{1} A_{n}$ bimetallic sites are isolated. They are called singly dispersed bimetallic sites.

a

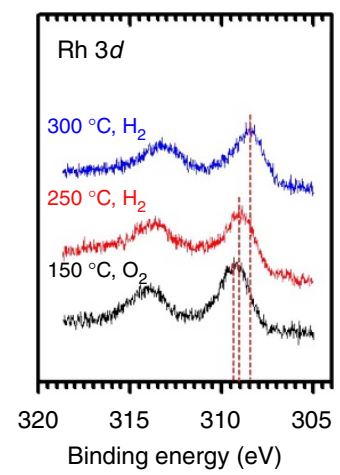

b

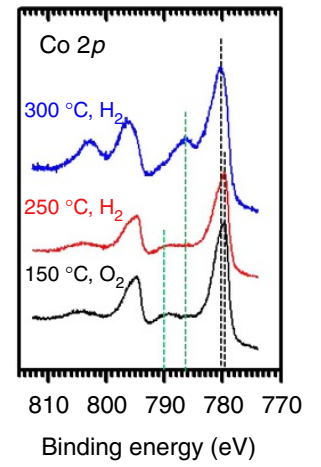

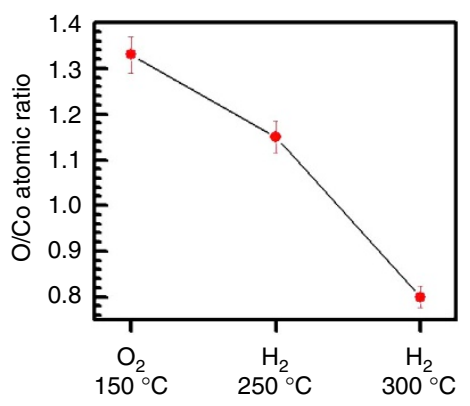

d

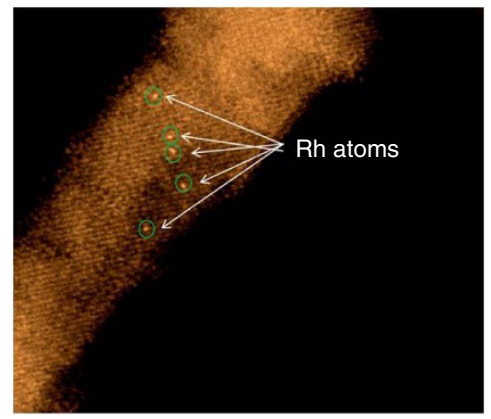

Figure 3 | In situ studies of surface chemistry. In situ studies of surface chemistry of the catalyst precursor in the preparation of the catalysts of singly dispersed $\mathrm{Rh}_{1} \mathrm{Co}_{3}$ bimetallic sites with ambient pressure XPS. (a) Rh 3d photoemission features during oxidation and reduction processes as marked. (b) Co $2 p$ photoemission features during oxidation and reduction. (c) Evolution of $\mathrm{O} / \mathrm{Co}$ atomic ratio under different reaction conditions; the error bar is $\pm 5 \%$ of the measured data. (d) HAADF-STEM image $(14 \times 11 \mathrm{~nm})$ of $\mathrm{Rh}_{1} \mathrm{Co}_{3} / \mathrm{CoO}$ prepared with oxidation at $150{ }^{\circ} \mathrm{C}$ in $5 \% \mathrm{O}_{2}$ and reduction at $300{ }^{\circ} \mathrm{C}$ in $5 \% \mathrm{H}_{2}$; the bright spots are $\mathrm{Rh}$ atoms of $\mathrm{Rh}_{1} \mathrm{Co}_{3}$ catalytic sites; $\mathrm{Rh}_{1} \mathrm{Co}_{3}$ sites are singly dispersed.

case, the guest metal atom $\mathrm{M}$ still bonds to the surface oxygen atoms instead of the surface metal atom(s) A; thus, no bimetallic $\mathrm{M}_{1} \mathrm{~A}_{n}$ site is formed. Therefore, an appropriate reduction of the catalyst precursor $\mathrm{M}_{1} \mathrm{O}_{n} / \mathrm{A}_{x} \mathrm{O}_{y}$ is crucial for the preparation of a catalyst of isolated $\mathrm{M}_{1} \mathrm{~A}_{n}$ bimetallic sites, $\mathrm{M}_{1} \mathrm{~A}_{n} / \mathrm{A}_{x} \mathrm{O}_{y}$.

$\mathrm{Co}_{3} \mathrm{O}_{4}$ was chosen as one example of oxide support $\left(\mathrm{A}_{x} \mathrm{O}_{y}\right)$. It generates oxygen vacancies on its surface readily when reduced in a reducing environment ${ }^{6,7}$. Reduction of nitric oxide with $\mathrm{CO}$ was used as a probing reaction. $\mathrm{Co}_{3} \mathrm{O}_{4}$ nanorods were synthesized through a colloidal method ${ }^{8-10}$. Rh atoms were introduced to the surface of $\mathrm{Co}_{3} \mathrm{O}_{4}$ nanorods through precipitation of $\mathrm{Rh}^{3+}$ in the format of $\mathrm{Rh}(\mathrm{OH})_{Z}$ species (Fig. $2 \mathrm{~b}$ ). $\mathrm{Rh}(\mathrm{OH})_{Z}$ weakly binds to the surface of $\mathrm{Co}_{3} \mathrm{O}_{4}$. Evolution of chemical environment of $\mathrm{Rh}$ atoms and the surface of cobalt oxide during appropriate oxidation and reduction steps was tracked with an in situ ambient pressure X-ray photoelectron spectroscopy (AP-XPS) ${ }^{11}$. For all in situ studies of this work, data were collected while gaseous reactants remained around a catalyst at a certain temperature.

During oxidation in $\mathrm{O}_{2}, \mathrm{Rh}$ atoms are at a cationic state with a high binding energy of Rh $3 d_{5 / 2}$ at $309.4 \mathrm{eV}$ (Fig. 3a) ${ }^{12}$. Upon the formation of $\mathrm{Rh}_{1} \mathrm{O}_{n}$ species on $\mathrm{Co}_{3} \mathrm{O}_{4}$ at $150{ }^{\circ} \mathrm{C}$ in $\mathrm{O}_{2}$, reductions in $\mathrm{H}_{2}$ at different temperatures were performed. In the reduction at $250{ }^{\circ} \mathrm{C}$ in $5 \% \mathrm{H}_{2}$, Rh $3 d$ down-shifted by 0.4 to $309.0 \mathrm{eV}$ (Fig. 3a). After the reduction in $5 \% \mathrm{H}_{2}$ at $250{ }^{\circ} \mathrm{C}$, a following reduction in $\mathrm{H}_{2}$ at $300^{\circ} \mathrm{C}$ was performed to form isolated bimetallic sites of $\mathrm{Rh}_{1} \mathrm{Co}_{3}$, as is schematically shown in Fig. $2 \mathrm{~d}$. During the reduction at $300^{\circ} \mathrm{C}$, Rh $3 d_{5 / 2}$ further down-shifted by $0.5 \mathrm{eV}$ to $308.5 \mathrm{eV}$ (Fig. 3a). Down-shift of binding energy from 309.4 to $308.5 \mathrm{eV}$ clearly suggests a change of the binding environment of $\mathrm{Rh}$ atoms during the reduction. The down-shift to $308.5 \mathrm{eV}$ instead of $307.4 \mathrm{eV}$ of metallic $\mathrm{Rh}$ shows that $\mathrm{Rh}$ atoms of the catalyst upon a reduction at $300^{\circ} \mathrm{C}$ in $5 \% \mathrm{H}_{2}$ are not at a metallic state. Figure $4 \mathrm{~d}$ is the image of HAADF (high-angle annular dark-field) through STEM (scanning transmission electron microscopy) of $\mathrm{Rh}_{1} \mathrm{Co}_{3} / \mathrm{CoO}$ after catalysis at $400^{\circ} \mathrm{C}$, in which singly dispersed $\mathrm{Rh}$ atoms appear as separated spots with high contrast due to the larger atomic number of Rh atoms in contrast to Co (ref. 13). This is consistent with the single dispersion of $\mathrm{Rh}$ atoms of catalysts after catalysis at $400{ }^{\circ} \mathrm{C}$ confirmed with in situ EXAFS (Fig. 4a).

In situ EXAFS technique was used to track the evolution of the coordination environment of $\mathrm{Rh}$ atoms of the catalyst precursor along the reaction at $150{ }^{\circ} \mathrm{C}$ in $5 \% \mathrm{O}_{2}$, at $300{ }^{\circ} \mathrm{C}$ in $5 \% \mathrm{H}_{2}$ and at $400^{\circ} \mathrm{C}$ in the mixture of $\mathrm{NO}$ and $\mathrm{CO}$ (Fig. 4a, Table 1 and Supplementary Fig. 2). The fitted structural parameters of Co and $\mathrm{O}$ atoms coordinating to $\mathrm{Rh}$ atoms of catalyst particles being annealed at $150^{\circ} \mathrm{C}$ in $\mathrm{O}_{2}$ show that (1) Rh atoms of the catalyst precursor are singly dispersed and (2) these Rh atoms on the cobalt oxide only bond with oxygen atoms with a coordination number of $\sim 4-5$ (Table 1). EXAFS study performed on the catalyst upon reduction in $5 \% \mathrm{H}_{2}$ at $300{ }^{\circ} \mathrm{C}$ shows that $\mathrm{Rh}$ atoms 

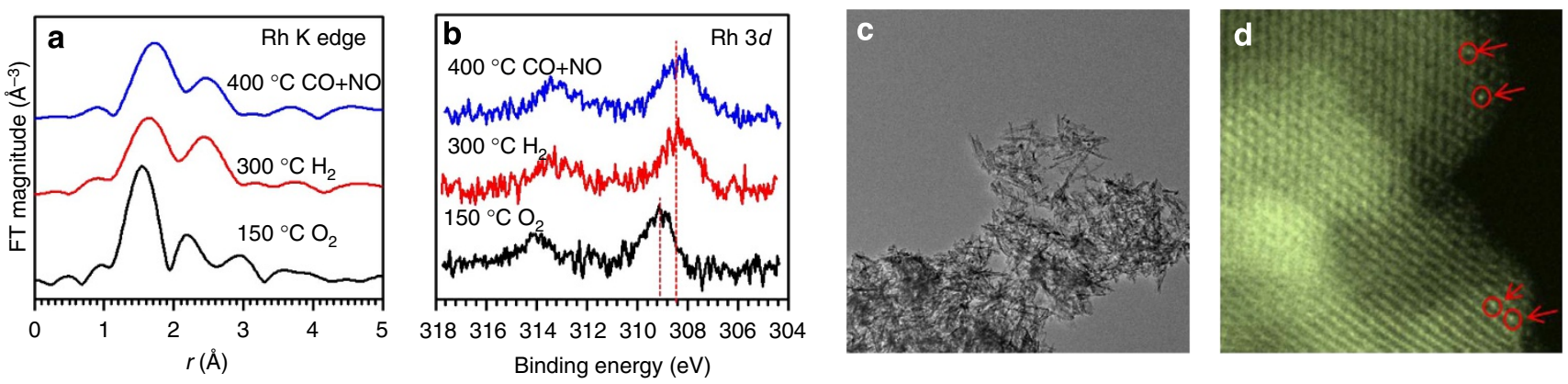

Figure 4 | Characterizations in the preparation of isolated bimetallic sites. Characterizations in the preparation of isolated bimetallic sites $\mathrm{Rh}_{1} \mathrm{Co}_{3} / \mathrm{CoO}$ and during catalysis by in situ EXAFS, in situ AP-XPS, and ex situ HAADF-STEM. (a) $r$-Space spectra of Rh $\mathrm{K}$ edge of catalyst precursor at $150{ }^{\circ} \mathrm{C}$ in $\mathrm{O}_{2}$ (black line), a following reduction at $300^{\circ} \mathrm{C}$ in $\mathrm{H}_{2}$ (red line) and during catalysis at $400^{\circ} \mathrm{C}$ from in situ EXAFS studies (blue line). (b) Photoemission feature of Rh $3 d$ of catalyst precursor at $150^{\circ} \mathrm{C}$ in $\mathrm{O}_{2}$ (black line), a following reduction at $300^{\circ} \mathrm{C}$ in $\mathrm{H}_{2}$ (red line) and during catalysis at $400{ }^{\circ} \mathrm{C}$ (blue line) from in situ AP-XPS studies. (c) TEM image $(700 \times 700 \mathrm{~nm})$ of $\mathrm{Rh}_{1} \mathrm{Co}_{3} / \mathrm{CoO}$ after catalysis. (d) HAADF-STEM image of the catalyst of isolated $\mathrm{Rh}_{1} \mathrm{Co}_{3}$ bimetallic sites after catalysis at $400^{\circ} \mathrm{C}$; the red arrows mark the $\mathrm{Rh}$ atoms that are singly dispersed on CoO.

Table 1 | Coordination numbers and bond lengths.

\begin{tabular}{|c|c|c|c|c|c|c|c|}
\hline $\begin{array}{l}\text { Reaction } \\
\text { temperature }\end{array}$ & Reactants & $\begin{array}{c}\text { Measurement } \\
\text { condition }\end{array}$ & $N(R h-0)$ & $N\left(R h-C_{0}\right)$ & $\mathbf{N}(\mathbf{R h}-\mathbf{R h})$ & $R(R h-0)(\AA)$ & $R\left(R h-C_{0}\right)(\AA)$ \\
\hline $150^{\circ} \mathrm{C}$ & $\mathrm{O}_{2}$ & $25^{\circ} \mathrm{C}, \mathrm{O}_{2}$ & $4.5 \pm 0.6$ & $0.3 \pm 0.4$ & 0 & $2.033 \pm 0.008$ & $2.55 \pm 0.03$ \\
\hline $300^{\circ} \mathrm{C}$ & $\mathrm{H}_{2}$ & $25^{\circ} \mathrm{C}, \mathrm{CO}+\mathrm{NO}$ & $2.6 \pm 1.0$ & $1.8 \pm 0.9$ & 0 & $2.13 \pm 0.04$ & $2.61 \pm 0.02$ \\
\hline $400^{\circ} \mathrm{C}$ & $\mathrm{CO}+\mathrm{NO}$ & $25^{\circ} \mathrm{C}, \mathrm{CO}+\mathrm{NO}$ & $1.7 \pm 0.5$ & $1.3 \pm 0.7$ & 0 & $2.15 \pm 0.03$ & $2.60 \pm 0.02$ \\
\hline
\end{tabular}

Coordination number of $\mathrm{O}, \mathrm{Co}$ and $\mathrm{Rh}$ atoms around a Rh atom and bond lengths of $\mathrm{Rh}-\mathrm{O}$ and $\mathrm{Rh}-\mathrm{Co}$ based on EXAFS studies of precursor of $\mathrm{Rh}{ }_{1} \mathrm{Co}_{3} / \mathrm{CoO}_{0}$ catalyst at $150{ }^{\circ} \mathrm{C}$ in $5 \% \mathrm{O}_{2}, 300{ }^{\circ} \mathrm{C}$ in $5 \% \mathrm{H}_{2}$ and of catalyst of $\mathrm{Rh}_{1} \mathrm{Co}_{3} / \mathrm{CoO}$ during catalysis at $400^{\circ} \mathrm{C}$ in a mixture of $5 \% \mathrm{CO}+5 \% \mathrm{NO}$.

still preserve their single dispersion $[\mathrm{CN}(\mathrm{Rh}-\mathrm{Rh})=0)]$ and bond with cobalt and oxygen atoms, $[\mathrm{CN}(\mathrm{Co}-\mathrm{Rh})=2.6$ and $\mathrm{CN}(\mathrm{O}-\mathrm{Rh})=1.8$ ]. The direct bonding of $\mathrm{Rh}$ to $\mathrm{Co}$ (Table 1) shows the formation of Rh-Co bonds. Since a $\mathrm{Rh}$ atom is isolated from other $\mathrm{Rh}$ atoms and bonds with Co atoms, we term the ensemble $\mathrm{Rh}_{1} \mathrm{Co}_{n}$ a singly dispersed bimetallic site or an isolated bimetallic site (Fig. 2d). The average coordination number of Co atoms directly bonded to a $\mathrm{Rh}$ atom is almost 2 based on EXAFS studies. For simplicity and consistence with the $\mathrm{Rh}_{1} \mathrm{Co}_{3}$ structure on $\mathrm{CoO}$ proposed through optimization in the following computational studies, $\mathrm{Rh}_{1} \mathrm{Co}_{3} / \mathrm{CoO}$ is used as the term of this type of isolated bimetallic sites in this communication.

It is noted that an over-reduction in $5 \% \mathrm{H}_{2}$ at a relatively high temperature of $400{ }^{\circ} \mathrm{C}$ forms metallic Co surface layers consisting of a small amount of $\mathrm{Rh}$ atoms, as is evidenced by the low binding energy of Co $2 p_{3 / 2}$ at $778.3 \mathrm{eV}$ and $\mathrm{Rh} 3 d_{5 / 2}$ at $307.2 \mathrm{eV}$ (Supplementary Fig. 1). However, AP-XPS studies show that a reduction in $5 \% \mathrm{H}_{2}$ at $250{ }^{\circ} \mathrm{C}$ does not form a $\mathrm{Rh}-\mathrm{Co}$ bond since $\mathrm{Rh} 3 d_{5 / 2}$ is still $\sim 309.0 \mathrm{eV}$ instead of $308.5 \mathrm{eV}$ (Fig. 3). Thus, an appropriate reduction temperature is the key for the formation of singly dispersed $\mathrm{Rh}_{1} \mathrm{Co}_{3}$ bimetallic sites.

Other than the evolution of coordination environment of $\mathrm{Rh}$ atoms in the preparation of a catalyst, one obvious change of the support, $\mathrm{Co}_{3} \mathrm{O}_{4}$ during reduction at $300^{\circ} \mathrm{C}$ in $5 \% \mathrm{H}_{2}$ is the formation of cobalt monoxide in the surface region, evidenced by the observed new peak of Co $2 p_{3 / 2}$ at $786.4 \mathrm{eV}$ (Fig. 3b). This peak is attributed to the characteristic satellite peak of Co $2 p_{3 / 2}$ of $\mathrm{Co}^{2+}$ in an octahedral coordination with oxygen atoms in $\mathrm{CoO}$ at $786.4 \mathrm{eV}$ (refs 14,15). Thus, by referring to the characteristic satellite peak of Co $2 p_{3 / 2}$ of $\mathrm{CoO}$ reported in literature ${ }^{14,15}$, the photoemission feature of Co $2 p_{3 / 2}$ collected at $300{ }^{\circ} \mathrm{C}$ in $5 \% \mathrm{H}_{2}$ is assigned to $\mathrm{CoO}$. In addition, the formation of $\mathrm{CoO}$ is also supported by the $\mathrm{O} / \mathrm{Co}$ atomic ratio of the catalyst experiencing a reduction at $300^{\circ} \mathrm{C}$ in $5 \% \mathrm{H}_{2}, 0.80$ (Fig. 3c), which was measured by taking the stoichiometric ratio of $\mathrm{Co}_{3} \mathrm{O}_{4}, 1.33$ at room temperature as a reference to calibrate the measured atomic ratios (O/Co).

As shown in Supplementary Table 1, the theoretical atomic ratio of all $\mathrm{Rh}$ atoms to all $\mathrm{Co}$ atoms of the topmost layer of $\mathrm{Co}$ atoms of $\mathrm{CoO}$ nanoparticles is $1.40 \%$. The measured ratios of the catalyst during catalysis at $150{ }^{\circ} \mathrm{C}$ and $400{ }^{\circ} \mathrm{C}$ are 1.26 and $1.25 \%$, respectively (Supplementary Table 1), which are quite close to the calculated ideal value, $1.40 \%$ (Supplementary Methods). These studies suggest that $\mathrm{Rh}$ atoms are mainly located on the topmost surface of catalyst particles without obvious thermal diffusion to deep layers. More information on the calculation of these atomic ratios of $\mathrm{Rh}$ to Co can be found in Supplementary Methods and Supplementary Figs 11-14.

Catalytic performances of isolated and continuous bimetallic sites. After the oxidation of the catalyst precursor in $5 \% \mathrm{O}_{2}$ at $150{ }^{\circ} \mathrm{C}$ with a following reduction at $300^{\circ} \mathrm{C}$ in $5 \% \mathrm{H}_{2}$, the catalyst was cooled to $80^{\circ} \mathrm{C}$ in $5 \% \mathrm{H}_{2}$. Once the $5 \% \mathrm{H}_{2}$ was purged, $30 \mathrm{ml} \mathrm{min}^{-1} 10 \% \mathrm{CO}$ (balanced with Ar), $20 \mathrm{ml} \mathrm{min}^{-1} 5 \% \mathrm{NO}$ (balanced with Ar) and $10 \mathrm{ml} \mathrm{min}^{-1} 99.999 \%$ Ar were mixed and then introduced. Measurements of catalytic performance on the catalyst of isolated $\mathrm{Rh}_{1} \mathrm{Co}_{3}$ sites anchored on $\mathrm{CoO}, \mathrm{Rh}_{1} \mathrm{Co}_{3} /$ $\mathrm{CoO}$ were performed in a fixed-bed flow reactor. $\mathrm{N}_{2} \mathrm{O}$ is the by-product of this reaction. $\mathrm{Rh}_{1} \mathrm{Co}_{3} / \mathrm{CoO}$ exhibits a catalytic selectivity of $100 \%$ for the production of $\mathrm{N}_{2}$ at a temperature as low as $110^{\circ} \mathrm{C}$ (Fig. 5a).

$\mathrm{Rh}-\mathrm{Co}$ bimetallic nanoparticles supported on $\mathrm{SiO}_{2}, \mathrm{Rh}-\mathrm{Co}$ bimetallic nanoparticles supported on $\mathrm{CoO}$ and a pure $\mathrm{CoO}$ catalyst were prepared with the details described in the section of method. The formation of Rh-Co alloy NP supported on $\mathrm{CoO}$ was confirmed with TEM (Supplementary Fig. 3) and XRD (Supplementary Fig. 4). Rh-Co bimetallic nanoparticle supported 


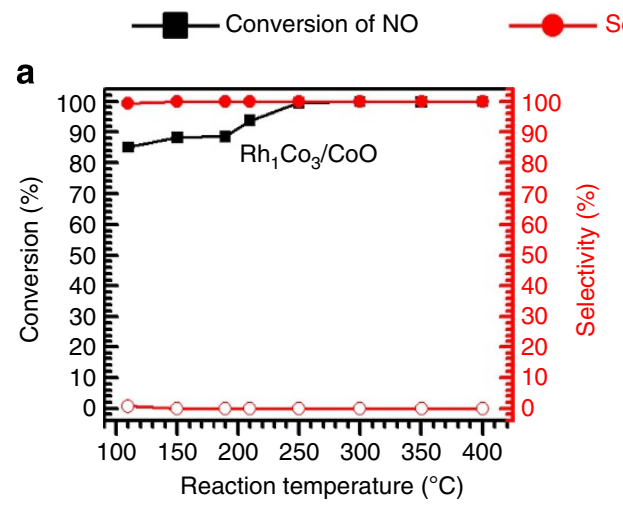

Selectivity to $\mathrm{N}_{2} \quad-\mathrm{O}-$ Selectivity to $\mathrm{N}_{2} \mathrm{O}$

C

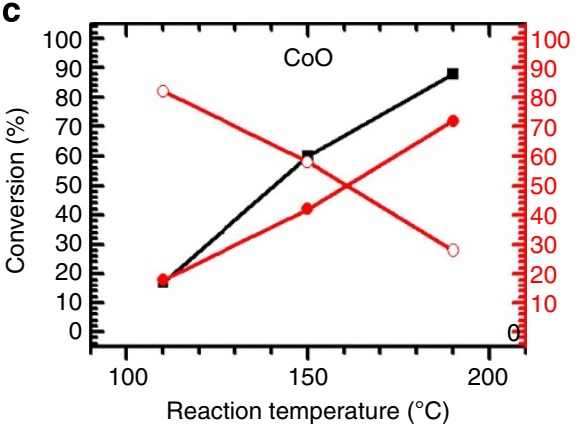

e

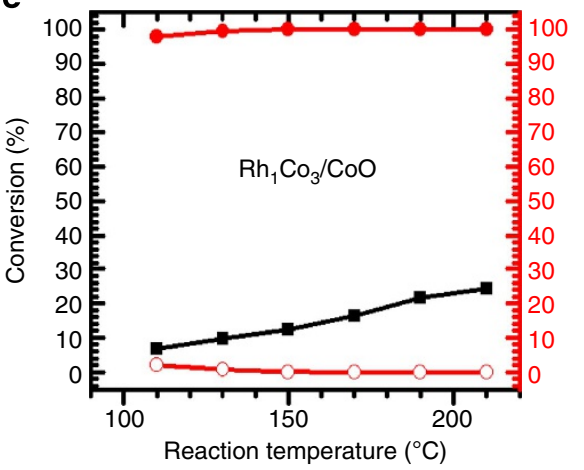

b

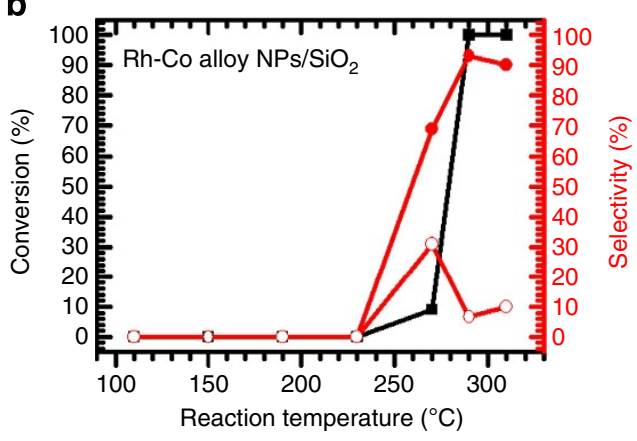

d

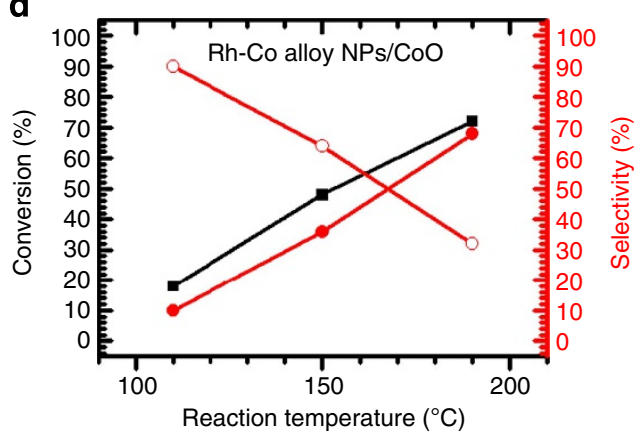

f

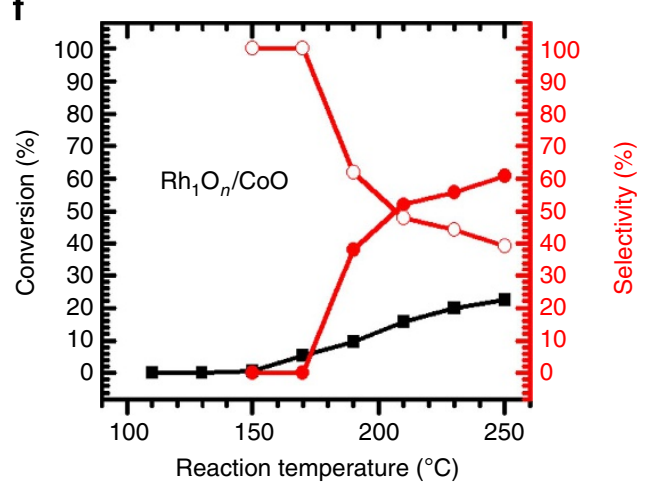

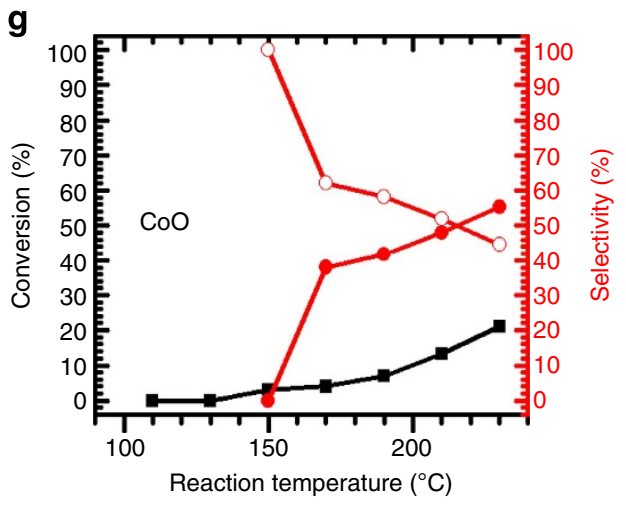

Figure 5 | Catalytic performances of catalysts measured under different conditions. (a) $\mathrm{Rh}_{1} \mathrm{Co}_{3} / \mathrm{CoO}$, (b) Rh-Co alloy nanoparticles (2.5 nm) supported on $\mathrm{SiO}_{2}$, (c) pure $\mathrm{CoO}$ and (d) Rh-Co bimetallic nanoparticles supported on CoO. Catalytic activity and selectivity of these catalysts (a-d) were measured with the exactly same condition: mixture of $20 \mathrm{ml} \mathrm{min}^{-1} 15 \% \mathrm{NO}$ balanced with $\mathrm{Ar}, 30 \mathrm{ml} \mathrm{min}^{-1} 10 \% \mathrm{CO}$ and $10 \mathrm{ml} \mathrm{min}^{-1} 99.999 \% \mathrm{Ar} ; 10 \mathrm{mg}$ of a catalyst was used in each catalytic measurement. (e-g) Catalytic performance $5 \mathrm{mg}$ of $\mathrm{Rh}_{1} \mathrm{Co}_{3} / \mathrm{CoO}_{1} 5 \mathrm{mg}$ of $\mathrm{Rh}_{1} \mathrm{O}_{n} / \mathrm{CoO}_{\text {and }} 10 \mathrm{mg}$ of $\mathrm{CoO}$ at kinetic controlled region (conversion is lower than 20\%); for these measurements in kinetics-controlled regime, $80 \mathrm{ml} 15 \%$ NO (balanced with Ar) and $12 \mathrm{ml}$ pure $\mathrm{CO}$ were mixed and introduced into the reactor.

on $\mathrm{SiO}_{2}$ is not active at any temperatures $<250{ }^{\circ} \mathrm{C}$ (Fig. 5b). In addition, the activity and selectivity for the production of $\mathrm{N}_{2}$ on $\mathrm{Rh}-\mathrm{Co}$ bimetallic nanoparticles supported on $\mathrm{CoO}$ at $110^{\circ} \mathrm{C}$ are only $20 \%$ and $10 \%$, respectively (Fig. 5 d). Compared with $\mathrm{Rh}-\mathrm{Co}$ bimetallic nanoparticles supported on $\mathrm{CoO}$, obviously the isolated bimetallic sites $\mathrm{Rh}_{1} \mathrm{Co}_{3}$ supported on $\mathrm{CoO}$ exhibit an outstanding 
catalytic performance in terms of high catalytic activity and $100 \%$ selectivity for production of $\mathrm{N}_{2}$ at a temperature as low as $110^{\circ} \mathrm{C}$ (Fig. 5a). Supplementary Table 2 lists catalytic performances at $110^{\circ} \mathrm{C}$ measured under kinetics controlled regime (Fig. 5e-g). Clearly, isolated $\mathrm{Rh}_{1} \mathrm{Co}_{3}$ bimetallic sites anchored on $\mathrm{CoO}$ $\left(\mathrm{Rh}_{1} \mathrm{Co}_{3} / \mathrm{CoO}\right)$ exhibit a much higher activity than $\mathrm{Rh}-\mathrm{Co}$ bimetallic nanoparticles supported on $\mathrm{SiO}_{2}$, pure $\mathrm{CoO}$ and $\mathrm{Rh}-$ Co bimetallic nanoparticles supported on $\mathrm{CoO}$. It is noted that $\mathrm{Rh}$ nanoparticles ${ }^{16}$ or Rh-based bimetallic nanoparticles ${ }^{17-20}$ and $\mathrm{Rh}$ single crystals ${ }^{21}$ are not active at a temperature $<240^{\circ} \mathrm{C}$; selectivities for the production of $\mathrm{N}_{2}$ on $\mathrm{Rh}$ nanoparticles at $240{ }^{\circ} \mathrm{C}$ (ref. 16) and $\mathrm{Rh}(100)$ at $255^{\circ} \mathrm{C}$ (ref. 21 ) are only $\sim 30 \%$ and $\sim 25 \%$, respectively. Overall, the isolated bimetallic sites $\mathrm{Rh}_{1} \mathrm{Co}_{3}$ of $\mathrm{Rh}_{1} \mathrm{Co}_{3} / \mathrm{CoO}$ exhibit an outstanding catalytic performance in terms of quite high catalytic activity and $100 \%$ selectivity for the reduction of $\mathrm{NO}$ to $\mathrm{N}_{2}$ at a temperature as low as $110^{\circ} \mathrm{C}$.

In situ AP-XPS studies of the catalyst during catalysis at a temperature up to $400{ }^{\circ} \mathrm{C}$ showed that $\mathrm{Rh}$ atoms of $\mathrm{Rh}_{1} \mathrm{Co}_{3} / \mathrm{CoO}$ catalyst remains at its oxidizing state (Fig. $4 \mathrm{~b}$ ). The high binding energy of $\mathrm{Rh} 3 d$ of isolated $\mathrm{Rh}_{1} \mathrm{Co}_{3}$ sites anchored on $\mathrm{CoO}$, $308.5 \mathrm{eV}$, suggests the cationic nature of the $\mathrm{Rh}$ atoms in isolated bimetallic sites during catalysis at $400^{\circ} \mathrm{C}$. The preservation of single dispersion of the $\mathrm{Rh}$ atoms and the coordination of Co to $\mathrm{Rh}$ were supported by in situ studies of EXAFS during catalysis (Fig. 4a and Table 1) and ex situ studies of the catalyst after catalysis at $400^{\circ} \mathrm{C}$ using HAADF-STEM (Fig. 4d). These characterizations suggest that the isolated bimetallic sites are preserved during catalysis and responsible for the high activity and $100 \%$ selectivity for $\mathrm{N}_{2}$ production. In addition, catalytic performances of $\mathrm{Rh}_{1} \mathrm{Co}_{3} / \mathrm{CoO}$ and pure $\mathrm{CoO}$ under kineticscontrolled regions were measured (Fig. 5e,g). By using the number of $\mathrm{Rh}$ atoms as the number of $\mathrm{Rh}_{1} \mathrm{Co}_{3}$ sites, turnover frequencies (TOFs) of the production of $\mathrm{N}_{2}$ were calculated and listed in Supplementary Table 2. The turnover frequency of $\mathrm{Rh}_{1} \mathrm{Co}_{3} / \mathrm{CoO}$ at $110^{\circ} \mathrm{C}$ is $4.4 \mathrm{~N}_{2}$ molecules per bimetallic site per second.

To confirm the importance of direct bonding of Co atoms to a $\mathrm{Rh}$ atom in $\mathrm{Rh}_{1} \mathrm{Co}_{3} / \mathrm{CoO}$, catalyst $\mathrm{Rh}_{1} \mathrm{O}_{n} / \mathrm{CoO}$ was synthesized with the method described in the Methods section. A two-step method was used in the preparation of $\mathrm{Rh}_{1} \mathrm{O}_{n} / \mathrm{CoO}$. CoO substrate was prepared by annealing $\mathrm{Co}_{3} \mathrm{O}_{4}$ to $300^{\circ} \mathrm{C}$ in $5 \%$ $\mathrm{H}_{2}$; the phase transformation was confirmed with XRD; in the second step $\mathrm{Rh}$ cations are loaded to the surface of $\mathrm{CoO}$ through deposition-precipitation with a following calcination in $\mathrm{H}_{2}$ at $200^{\circ} \mathrm{C}$ for $1 \mathrm{~h}$; the adsorbed $\mathrm{Rh}(\mathrm{OH})_{z}$ species were transferred to $\mathrm{Rh}_{1} \mathrm{O}_{n}$. The existence of $\mathrm{Rh}$ atoms on the surface was supported with the preservation of $\mathrm{Rh} / \mathrm{Co}$ ratio (all $\mathrm{Rh}$ atoms to all Co atoms of the topmost layer of $\mathrm{Co}$ of $\mathrm{CoO}$ ) measured with AP-XPS before and after annealing in $\mathrm{H}_{2}$ at $200{ }^{\circ} \mathrm{C}$.

The difference in coordination environment of $\mathrm{Rh}_{1}$ between $\mathrm{Rh}_{1} \mathrm{Co}_{3} / \mathrm{CoO}$ and $\mathrm{Rh}_{1} \mathrm{O}_{\mathrm{n}} / \mathrm{CoO}$ results in a distinct difference in catalytic performance. Figure $5 \mathrm{e}, \mathrm{f}$ present the catalytic performances of $\mathrm{Rh}_{1} \mathrm{Co}_{3} / \mathrm{CoO}$ and $\mathrm{Rh}_{1} \mathrm{O}_{n} / \mathrm{CoO}$ measured under kinetics-control regime. $\mathrm{Rh}_{1} \mathrm{O}_{n} / \mathrm{CoO}$ is not active at a temperature of $150^{\circ} \mathrm{C}$ and lower. But $\mathrm{Rh}_{1} \mathrm{Co}_{3} / \mathrm{CoO}$ is active at $110^{\circ} \mathrm{C}$. In addition, $\mathrm{Rh}_{1} \mathrm{O}_{n} / \mathrm{CoO}$ exhibits low selectivity to $\mathrm{N}_{2}$ production in the temperature range of $150-200{ }^{\circ} \mathrm{C}$. But $\mathrm{Rh}_{1} \mathrm{Co}_{3} / \mathrm{CoO}$ exhibits a selectivity of $100 \%$ for the reduction of $\mathrm{NO}$ to $\mathrm{N}_{2}$ in this temperature range. The distinct difference between $\mathrm{Rh}_{1} \mathrm{O}_{n} / \mathrm{CoO}$ and $\mathrm{Rh}_{1} \mathrm{Co}_{3} / \mathrm{CoO}$ in their catalytic performances results from two factors. One is the difference in geometry; the $\mathrm{Rh}-\mathrm{O}-\mathrm{Co}$ of $\mathrm{Rh}_{1} \mathrm{O}_{n} / \mathrm{CoO}$ is different from a bimetallic site of $\mathrm{Rh}_{1} \mathrm{Co}_{3} / \mathrm{CoO}$. The existence of a $\mathrm{Co}-\mathrm{Rh}_{1}-\mathrm{Co}$ on $\mathrm{Rh}_{1} \mathrm{Co}_{3} / \mathrm{CoO}$ allows for a strong bonding of two NO molecules (see the following DFT calculations) and thus readily activate NO molecules compared with $\mathrm{Rh}_{1} \mathrm{O}_{n} / \mathrm{CoO}$. Thus, catalyst of singly dispersed bimetallic sites $\mathrm{Rh}_{1} \mathrm{Co}_{3}$ is different from the singly dispersed $\mathrm{Rh}_{1}$ atoms that solely bond to oxygen atoms of the oxide support ${ }^{22-24}$.

Location of $\mathbf{R h}$ atoms on CoO. To understand the catalytic mechanism of $\mathrm{NO}$ reduction with $\mathrm{CO}$ on singly dispersed $\mathrm{Rh}_{1} \mathrm{Co}_{3}$ anchored on cobalt monoxide, computational modelling of the adsorption, activation and reaction pathway using periodic density functional theory (DFT) was performed. DFT calculations were done for interpretation of the binding environment of Rh atoms (Fig. 6). A Rh atom could anchor to the original position of a missed oxygen (the location of an oxygen vacancy) of $\mathrm{CoO}$ in Fig. 6a and thus bond to cobalt atoms; alternatively, it could replace a $\mathrm{Co}$ atom of $\mathrm{CoO}$ therefore bond to oxygen atoms (Fig. 6c). As shown in Fig. 6a, DFT calculations show that the energy change for filling an oxygen vacancy with a $\mathrm{Rh}$ atom is $-5.39 \mathrm{eV}$, while the energy change for the replacement of a Co atom with a $\mathrm{Rh}$ atom on surface is $-3.86 \mathrm{eV}$. Obviously, filling an oxygen vacancy of $\mathrm{CoO}$ with a guest $\mathrm{Rh}$ atom is energetically favourable than replacing a Co atom of the surface with a guest $\mathrm{Rh}$ atom. This is consistent with the in situ measurements of EXAFS of the catalyst in $5 \% \mathrm{H}_{2}$ at $300{ }^{\circ} \mathrm{C}$ showing that Rh atoms bond with Co atoms (Fig. 4a and Table 1). Supplementary Fig. 5b is the optimized structure in which the guest $\mathrm{Rh}$ atom fills an oxygen vacancy and thus bonds with three cobalt atoms and one oxygen atom.

Optimization of $\mathbf{R h}_{1} \mathrm{Co}_{3}$ structural model. In rock-salt $\mathrm{CoO}$ crystal, each $\mathrm{Co}^{2+}$ is coordinated by six $\mathrm{O}^{2-}$ ions in an octahedral crystal field with Co-O distance of $2.13 \AA$. The $(011)$ surface of $\mathrm{CoO}$ with oxygen vacancies can be viewed as an assembled -O-Co- $\square-\mathrm{Co}-\mathrm{O}-\mathrm{Co}-$ chain (Supplementary Fig. $5 \mathrm{a}$ ). When a $\mathrm{Rh}$ atom substitutes an oxygen atom on the CoO surface, the $R h_{1}$ atom is not only relocated by $1.13 \AA$ above the vacancy centre (the original oxygen vacancy $\square$, marked with a small light blue ball in Supplementary Fig. 5a), but also moved closer to an oxygen atom shown as a red ball (Supplementary Fig. $5 \mathrm{~b})$ in the neighbouring chain with a $\mathrm{Rh}_{1}-\mathrm{O}$ distance of $2.04 \AA$, which is close to a Co-O single bond estimated as $1.9 \AA$. As a result, the $\mathrm{Rh}_{1}$ atom only bonds with one neighbouring $\mathrm{O}$ atom, while other $\mathrm{O}$ atoms are far from the $\mathrm{Rh}_{1}$ atom by more than $3.3 \AA$ away. In addition, around a $\mathrm{Rh}_{1}$ atom, there are three Co atoms $\mathrm{Co}(3), \mathrm{Co}(5), \mathrm{Co}(7)$ marked with stars with a $\mathrm{Rh}-\mathrm{Co}$ distance averagely $2.54 \AA$ in Supplementary Fig. 5b. However, other three cobalt atoms, $\mathrm{Co}(2), \mathrm{Co}(4)$ and $\mathrm{Co}(6)$ around the $\mathrm{Rh}_{1}$ atom are far from the $\mathrm{Rh}_{1}$ at a distance of $\mathrm{Rh}_{1}-\mathrm{Co}(2)$ at $3.15 \AA$, $\mathrm{Rh}_{1}-\mathrm{Co}(4)$ at $2.81 \AA$ and $\mathrm{Rh}_{1}-\mathrm{Co}(6)$ at $3.15 \AA$. Therefore, the local coordination shell of $\mathrm{Rh}_{1}$ atom is referred as $\mathrm{Rh}_{1} \mathrm{Co}_{3}$; the three Co atoms directly coordinating to $\mathrm{Rh}_{1}$ of $\mathrm{Rh}_{1} \mathrm{Co}_{3}$ are $\mathrm{Co}(3)$, $\mathrm{Co}(5)$ and $\mathrm{Co}(7)$. This optimized geometry model will be used in all the following calculations.

Adsorption geometry of $\mathrm{NO}$ and $\mathrm{CO}$ on $\mathrm{Rh}_{1} \mathrm{Co}_{3} / \mathrm{CoO}$. As both the surface Rh and Co atoms can adsorb NO and CO, the preferred adsorption models of NO and CO (Supplementary Fig. $5 c-j$ ) were investigated through DFT calculations. Consistent with the orbital interaction analysis, the $\mathrm{NO}$ and $\mathrm{CO}$ interact with metal atoms through $\mathrm{N}$ - and $\mathrm{C}$-side, respectively. By optimizing the adsorption geometries of $\mathrm{NO}$ and $\mathrm{CO}$ on various sites with different end-on and bridging binding configurations, the adsorption modes and energies of $\mathrm{CO}$ and $\mathrm{NO}$ on the surface of a $\mathrm{Rh}_{1} \mathrm{Co}_{3} / \mathrm{CoO}$ catalyst were evaluated in the DFT calculations. It is found that adsorption of one NO molecule (Supplementary Fig. $5 c$ ) on $\mathrm{Rh}_{1}$ atom is slightly more favourable than that of one 
a

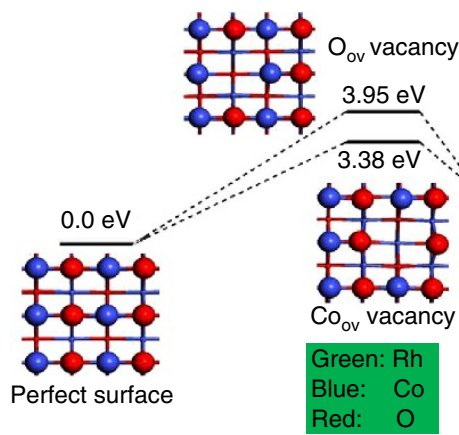

b

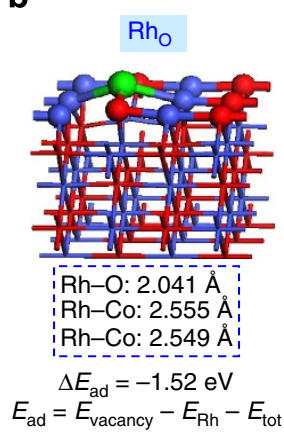

C

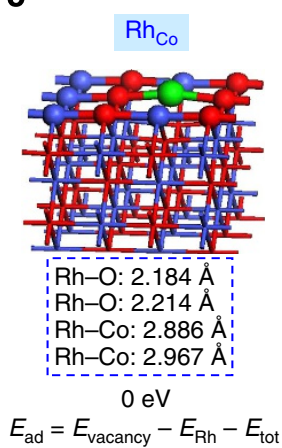

Figure 6 | Computational studies for understanding the site for anchoring a guest atom, Rh. (a) Evolution of energy of a surface defect (either $O$ vacancy, $\mathrm{O}_{\mathrm{vac}}$ or $\mathrm{Co}$ vacancy, $\mathrm{Co}_{\mathrm{vac}}$ ) while it is filled with a $\mathrm{Rh}$ atom. (b) Optimized structure upon filling $\mathrm{Rh}$ to oxygen vacancy (Rho); in this case the anchored $\mathrm{Rh}$ atom bonds with three cobalt atoms and thus a $\mathrm{Rh}_{1} \mathrm{Co}_{3}$ bimetallic site is formed. (c) Optimized structure upon replacing a cobalt atom with a $\mathrm{Rh}$ atom $\left(\mathrm{Rh}_{\mathrm{Co}_{0}}\right)$; in this case the anchored $\mathrm{Rh}$ atom bonds with four oxygen atoms but not with any cobalt atoms; thus it does not form a $\mathrm{Rh}_{1} \mathrm{Co}_{3}$ bimetallic site if Rh replaces a Co atom.

a

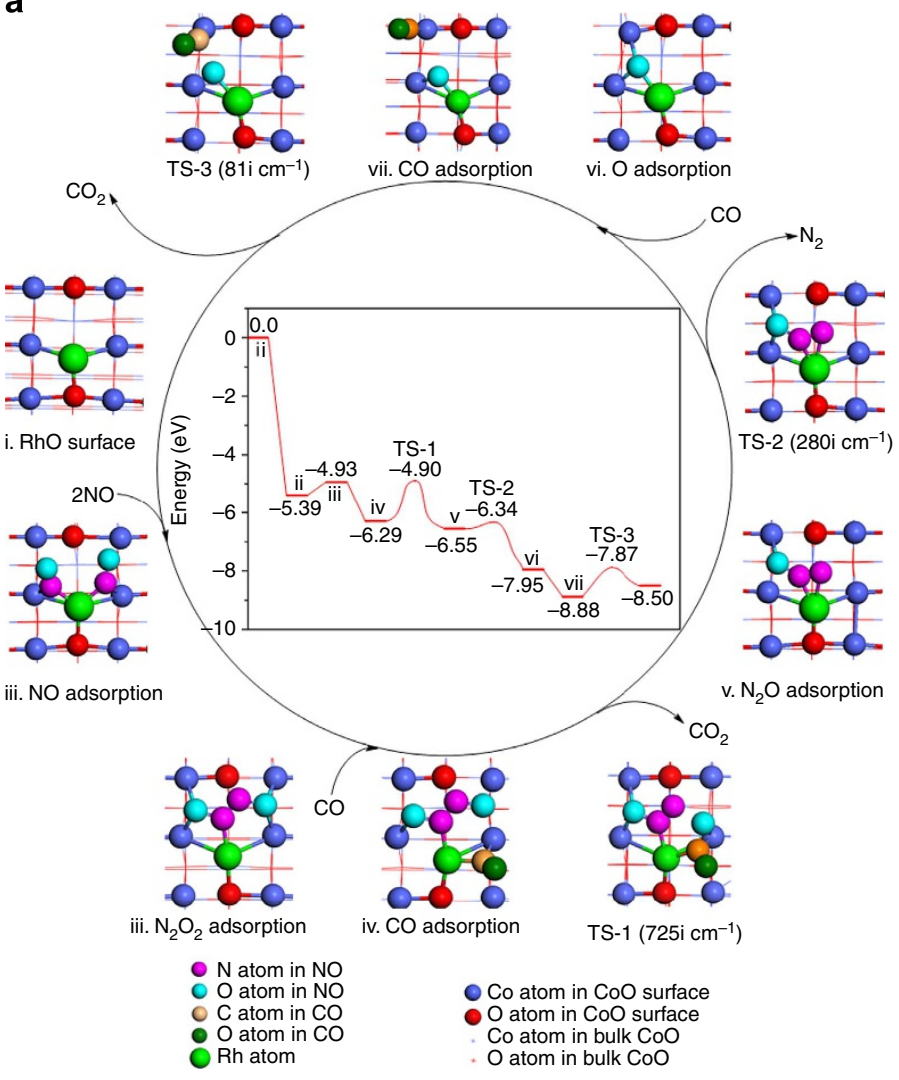

b
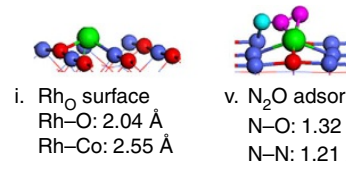

v. $\mathrm{N}_{2} \mathrm{O}$ adsorption

$\mathrm{N}-\mathrm{O}: 1.32 \AA$

$\mathrm{N}-\mathrm{N}: 1.21 \AA$

$\mathrm{Rh}-\mathrm{N}_{\mathrm{NO}}: 1.96 \AA$

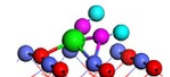

ii. NO adsorption $\mathrm{N}-\mathrm{O}: 1.26 \AA$

$\mathrm{Rh}-\mathrm{N}: 1.93 \AA$

Co-N: $1.85 \AA$

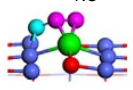

TS-2

$\mathrm{N}-\mathrm{O}: 1.50 \AA$

$\mathrm{N}-\mathrm{N}: 1.22 \AA$

$\mathrm{Rh}-\mathrm{N}_{\mathrm{NO}}: 2.02 \AA$

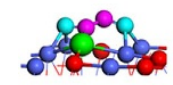

iii. $\mathrm{N}_{2} \mathrm{O}_{2}$ adsorption Co-N: $1.98 \AA$
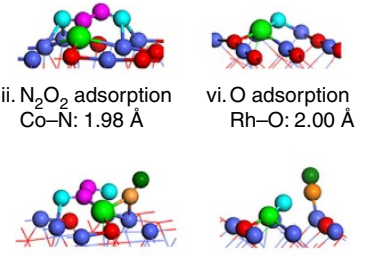

iv. CO adsorption

$\mathrm{Rh}-\mathrm{N}: 2.00 \AA$

$\mathrm{O}_{\mathrm{N} 2 \mathrm{O} 2}-\mathrm{C}: 2.74 \AA$

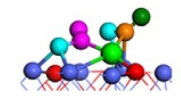

TS-1

Rh-N: $1.99 \AA$

$\mathrm{O}_{\mathrm{N} 2 \mathrm{O} 2}-\mathrm{C}: 1.40 \AA$
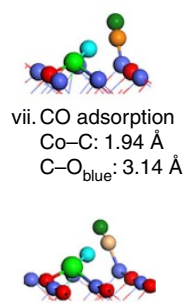

TS-3

Co-C: $1.93 \AA$

Figure 7 | Reaction pathway. Reaction pathway for reduction of $\mathrm{NO}$ with $\mathrm{CO}$ on the singly dispersed $\mathrm{Rh}_{1} \mathrm{CO}_{3}$ supported on $\mathrm{CoO}$ proposed from $\mathrm{DFT}$ calculations. (a) Reaction pathway and energy profile. (b) Calculated structural parameters of intermediates and transition states in the pathway.

CO molecule (Supplementary Fig. 5d). Because the singly dispersed $\mathrm{Rh}$ atom is not saturated in its coordination shell, co-adsorption is in fact more stable than mono-adsorption. Among all the possible co-adsorption models (Supplementary Fig. 5e-j), two NO molecules co-adsorbed on the $\mathrm{Co}-\mathrm{Rh}_{1}-\mathrm{Co}$ of $\mathrm{Rh}_{1} \mathrm{Co}_{3}$ is most stable (Supplementary Fig. 5e). Thus, $\mathrm{Rh}_{1} \mathrm{Co}_{3}$ adsorbing two NO molecules was used to simulate the reaction pathways and search transition states in the following catalysis studies. Similar to the results for $\mathrm{Rh}_{1} \mathrm{Co}_{3} / \mathrm{CoO}(011)$, DFT calculations of the adsorption energies of $\mathrm{NO}, \mathrm{NO}+\mathrm{NO}, \mathrm{CO}+\mathrm{CO}$ or
$\mathrm{CO}+\mathrm{NO}$ on $\mathrm{Rh}_{1} \mathrm{Co}_{3} / \mathrm{CoO}(001)$ (Supplementary Fig. 6) show that co-adsorption of two NO molecules on $\mathrm{Co}-\mathrm{Rh}_{1}-\mathrm{Co}$ of $\mathrm{Rh}_{1} \mathrm{Co}_{3} / \mathrm{CoO}$ are the strongest adsorption as well.

Reaction pathway. The reaction pathway was calculated for the reduction of $\mathrm{NO}$ with $\mathrm{CO}$ on a singly dispersed $\mathrm{Rh}_{1} \mathrm{Co}_{3}$ bimetallic site anchored on $\mathrm{CoO}$ (Fig. 7). Briefly, the $\mathrm{O}_{\mathrm{vac}}$ is filled by a single $\mathrm{Rh}$ atom to form a singly dispersed bimetallic site $\mathrm{Rh}_{1} \mathrm{Co}_{3}$ (step i), which can adsorb two NO molecules on the $\mathrm{Co}-\mathrm{Rh}_{1}-\mathrm{Co}$ atoms of 


\begin{tabular}{|c|c|c|}
\hline Reaction pathway & $\Delta E(\mathrm{eV})$ & $E_{\mathrm{a}}(\mathrm{eV})$ \\
\hline $\begin{array}{l}\text { 1) } 2 \mathrm{NO} \rightarrow 2 \mathrm{NO}^{*} \\
\text { 2) } 2 \mathrm{NO} \rightarrow \mathrm{N}_{2} \mathrm{O}_{2}^{*} \\
\text { 3) } \mathrm{CO} \rightarrow \mathrm{CO}^{\star} \\
\text { 4) } \mathrm{N}_{2} \mathrm{O}_{2}{ }^{*}+\mathrm{CO}^{\star} \rightarrow \mathrm{N}_{2} \mathrm{O}^{\star}+\mathrm{CO}_{2} \\
\text { 5) } \mathrm{N}_{2} \mathrm{O}^{\star} \rightarrow \mathrm{N}_{2}{ }^{*}+\mathrm{O}^{\star} \\
\text { 6) } \mathrm{CO} \rightarrow \mathrm{CO}^{*} \\
\text { 7) } \mathrm{CO}^{\star}+\mathrm{O}^{\star} \rightarrow \mathrm{CO}_{2}^{*}\end{array}$ & $\begin{array}{r}-5.39 \\
-4.93 \\
-0.71 \\
- \\
-1.70 \\
-1.07 \\
0.38\end{array}$ & $\begin{array}{l}- \\
- \\
- \\
1.39 \\
0.21 \\
- \\
1.01\end{array}$ \\
\hline $\begin{array}{l}\text { Calculated process energies }(\Delta E) \text { and acti } \\
\text { reduction of } N O \text { with } C O \text { on } R h_{1} C_{3} / C o O \\
\Delta E \text { is defined as the energy difference betw } \\
\text { barrier Ea is defined as the difference betw } \\
\text { of its corresponding initial state. }\end{array}$ & $\begin{array}{l}\text { (Ea) for these } \\
\text { of Fig. 7. Note: } \\
\text { ate and the ini } \\
\text { of the transiti }\end{array}$ & $\begin{array}{l}\text { ry steps in } t \\
\text { rocess ener } \\
\text { (2) Activati } \\
\text { and the ener }\end{array}$ \\
\hline
\end{tabular}

a $\mathrm{Rh}_{1} \mathrm{Co}_{3}$ site (step ii); two NO molecules couple on $\mathrm{Co}-\mathrm{Rh}_{1}-\mathrm{Co}$ to form a $\mathrm{N}_{2} \mathrm{O}_{2}$ intermediate (step iii) to facilitate the formation of intermediate $\mathrm{N}_{2} \mathrm{O}$; meanwhile one $\mathrm{CO}$ molecule can adsorb on the Co atom neighbouring to $\mathrm{Rh}_{1} \mathrm{Co}_{3}$ (step iv).

The first $\mathrm{CO}_{2}$ molecule is released after the adsorbed $\mathrm{CO}$ molecule couples with one $\mathrm{O}$ atom of $\mathrm{N}_{2} \mathrm{O}_{2}$ adsorbed on the Co- $\mathrm{Rh}_{1}$-Co site (TS-1). This coupling yields a $\mathrm{CO}_{2}$ molecule and forms an intermediate $\mathrm{N}_{2} \mathrm{O}$ remaining on the surface (step v). It is noted that the $\mathrm{N}-\mathrm{O}$ bond in the intermediate $\mathrm{N}_{2} \mathrm{O}$ stretches to form a transition state with a small barrier of $0.21 \mathrm{eV}$ (TS-2), which leads to a ready cleavage of $\mathrm{N}-\mathrm{O}$ bond of the intermediate $\mathrm{N}_{2} \mathrm{O}$ and then releases a $\mathrm{N}_{2}$ molecule and leaves an $\mathrm{O}$ atom on $\mathrm{Rh}_{1}$ (step vi). By adsorbing a second $\mathrm{CO}$ on a nearby Co atom (step vii) and then coupling to the left oxygen atoms on the $\mathrm{Rh}_{1}$ atom, a second $\mathrm{CO}_{2}$ molecule is released from the surface; thus a catalytic cycle is finished. In this catalytic cycle, the catalyst releases two $\mathrm{CO}_{2}$ molecules and one $\mathrm{N}_{2}$ molecule and then recovers its original surface structure (step i in Fig. 7). The inset of Fig. 7a presents the calculated energy profile with the partially reduced system as the reference for the energies in $\mathrm{eV}$. Figure $7 \mathrm{~b}$ lists the calculated structural parameters of intermediates and transition states of this pathway.

In this reaction pathway, the $\mathrm{Rh}_{1} \mathrm{Co}_{3}$ site plays a crucial role in the high activity and selectivity in reducing $\mathrm{NO}$ with $\mathrm{CO}$. The local coordination environment of the bimetallic site $\mathrm{Rh}_{1} \mathrm{Co}_{3}$ helps to activate the two NO molecules on $\mathrm{Co}-\mathrm{Rh}_{1}-\mathrm{Co}$ of $\mathrm{Rh}_{1} \mathrm{Co}_{3}$ through co-adsorption and coupling. The catalytic elementary steps, evolution of energies and activation barriers are listed in Table 2. Especially noteworthy is the extremely low activation barrier of $\mathrm{N}_{2} \mathrm{O}$ decomposition $(0.21 \mathrm{eV})$ to a $\mathrm{N}_{2}$ molecule on the $\mathrm{Rh}_{1} \mathrm{Co}_{3} / \mathrm{CoO}$ catalyst. Given the high reaction temperature, this step is virtually barrierless in terms of Gibbs free energies. Thus, these calculation results are quite consistent with the fact that the catalyst of $\mathrm{Rh}_{1} \mathrm{Co}_{3}$ bimetallic sites is active at a temperature as low as $110^{\circ} \mathrm{C}$ with a selectivity of $100 \%$ for production of $\mathrm{N}_{2}$.

Other than the formation of a $\mathrm{N}_{2}$ molecule through breaking $\mathrm{N}-\mathrm{O}$ bond of the intermediate $\mathrm{N}_{2} \mathrm{O}$ (v of Fig. 7), we further considered other pathways. For instance, $\mathrm{N}$ atom formed through dissociation of one of the two NO molecules (i of Supplementary Fig. 7) could couple with a $\mathrm{N}$ atom of another $\mathrm{NO}$ molecule that bonds to an oxygen vacancy through the oxygen atom of $\mathrm{NO}$ (ii of Supplementary Fig. 7); this coupling weakens $\mathrm{N}-\mathrm{O}$ bond of the adsorbed $\mathrm{NO}$ molecule and thus forms a $\mathrm{N}_{2}$ species strongly adsorbed on the $\mathrm{Rh}$ atom with a quite high adsorption energy (iv of Supplementary Fig. 7). The barrier of the transition state (iii of Supplementary Fig. 7) to form $\mathrm{N}_{2}$ molecule is $0.5 \mathrm{eV}$. However, the binding energy of $\mathrm{N}_{2}$ molecule on $\mathrm{Rh}$ atom is quite large (iv of Supplementary Fig. 7), which makes this pathway less favourable.

\section{Discussion}

To understand the difference in binding of NO molecules on isolated sites $\mathrm{Rh}_{1} \mathrm{Co}_{3}$ supported on $\mathrm{CoO}$ and surface of a $\mathrm{Rh}-\mathrm{Co}$ bimetallic nanoparticle supported on $\mathrm{CoO}$, structural models of $\mathrm{Rh}_{1} \mathrm{Co}_{3} / \mathrm{CoO}$ with one adsorbed $\mathrm{NO}$ molecule (Supplementary Fig. 8a) and $\mathrm{Rh}-\mathrm{Co}$ bimetallic nanoparticle/CoO with one adsorbed NO molecule (Supplementary Fig. 8b) were built. DFT calculations show that adsorption of a NO molecule on $\mathrm{Rh}$ atom of $\mathrm{Rh}_{1} \mathrm{Co}_{3}$ is definitely stronger than that on a zero-valent $\mathrm{Rh}(0)$ atom of a $\mathrm{Rh}-\mathrm{Co}$ bimetallic nanoparticle (Supplementary Table 3). Consistent with this difference, the calculated $\mathrm{N} \cdots \mathrm{Rh}$ distance of $\mathrm{Rh}_{1} \mathrm{Co}_{3} / \mathrm{CoO}$ is $\sim 0.03 \AA$ smaller in contrast to that of $\mathrm{Rh}-\mathrm{Co}$ bimetallic nanoparticle/CoO. These differences suggest that the $\mathrm{Rh}_{1} \mathrm{Co}_{3} / \mathrm{CoO}$ catalyst can readily activate $\mathrm{NO}$ compared with $\mathrm{Rh}-\mathrm{Co}$ bimetallic nanoparticle/CoO.

The computed electron density difference maps of the two different fragments on $\mathrm{Rh}_{1} \mathrm{Co}_{3} / \mathrm{CoO}$ and $\mathrm{Rh}-\mathrm{Co}$ bimetallic nanoparticle/CoO are shown in Supplementary Fig. 8c and d, respectively. In these plots (Supplementary Fig. 8c and $\mathrm{d}$ ), a decrease in electron density is shown in blue, electron enrichment indicated in red; white region indicates little change in electron density. The more red colour between $\mathrm{N}$ and $\mathrm{Rh}$ in $\mathrm{Rh}_{1} \mathrm{Co}_{3} / \mathrm{CoO}$ (Supplementary Fig. 8c) than the one in the $\mathrm{Rh}-\mathrm{Co}$ bimetallic nanoparticle supported on $\mathrm{CoO}$ (Supplementary Fig. 8d) shows that the $\mathrm{Rh}-\mathrm{N}$ bond on $\mathrm{Rh}_{1} \mathrm{Co}_{3} / \mathrm{CoO}$ is stronger than that on $\mathrm{Rh}-$ Co nanoparticles supported on $\mathrm{CoO}$. Thus the charge transfer from $\mathrm{NO}$ to $\mathrm{Rh}$ atoms of $\mathrm{Rh}_{1} \mathrm{Co}_{3} / \mathrm{CoO}$ is larger than that on $\mathrm{Rh}-$ Co bimetallic nanoparticle/CoO. The calculated Bader charges (Supplementary Table 4) revealed that the $\mathrm{Rh}_{1}$ single atom of $\mathrm{Rh}_{1} \mathrm{Co}_{3} / \mathrm{CoO}$ carries positive charge upon adsorption of $\mathrm{NO}$ while the $\mathrm{Rh}$ atom in $\mathrm{Rh}-\mathrm{Co}$ alloy $\mathrm{NP} / \mathrm{CoO}$ carries negative charge upon $\mathrm{NO}$ adsorption. The positive charge on $\mathrm{Rh}_{1}$ of a singly dispersed $\mathrm{Rh}_{1} \mathrm{Co}_{3}$ site allows more electron transfer from $\mathrm{NO}$, which enhances the $\mathrm{Rh}-\mathrm{N}$ bond and thus largely weakens the $\mathrm{N}-\mathrm{O}$ bond of $\mathrm{NO}$ molecule on $\mathrm{Rh}_{1} \mathrm{Co}_{3}$.

The spin-polarized projected density of states (PDOS) of the $4 d$ states of $\mathrm{Rh}$ atom and the $\mathrm{N}-2 p$ and $\mathrm{O}-2 p$ orbitals of adsorbed NO on $\mathrm{Rh}_{1} \mathrm{Co}_{3} / \mathrm{CoO}$ and $\mathrm{Rh}-\mathrm{Co}$ bimetallic nanoparticle/CoO are shown in Supplementary Fig. 8e and f, respectively. The spin-polarized projected density of states show that below the Fermi level $\left(E_{\mathrm{F}}\right) \mathrm{Rh} 4 d$ states in $\mathrm{Rh}_{1} \mathrm{Co}_{3} / \mathrm{CoO}$ catalyst are more localized than the Rh $4 d$ states in Rh-Co bimetallic nanoparticle/ CoO. In addition, $\mathrm{Rh} 4 d$ states in $\mathrm{Rh}_{1} \mathrm{Co}_{3} / \mathrm{CoO}$ (Supplementary Fig. 8e) are mixed better with $\mathrm{N} 2 p$ and $\mathrm{O} 2 p$ states than Rh $4 d$ states in $\mathrm{Rh}-\mathrm{Co}$ bimetallic nanoparticle/CoO (Supplementary Fig. 8f), indicating a strong interaction between $\mathrm{Rh}_{1}$ atom of $\mathrm{Rh}_{1} \mathrm{Co}_{3}$ and the adsorbed NO molecule.

One critical difference between a singly dispersed $\mathrm{Rh}_{1} \mathrm{Co}_{3}$ site anchored on $\mathrm{CoO}$ and a $\mathrm{Rh}-\mathrm{Co}$ bimetallic nanoparticle supported on $\mathrm{CoO}$ is the $100 \%$ selectivity for production of $\mathrm{N}_{2}$ in reduction of $\mathrm{NO}$ with $\mathrm{CO}$ on $\mathrm{Rh}_{1} \mathrm{Co}_{3}$ (Fig. 5a). On $\mathrm{Rh}-\mathrm{Co}$ bimetallic nanoparticle supported on $\mathrm{CoO}$ (Fig. 5d), however, selectivity for production of $\mathrm{N}_{2}$ is only $10 \%$. To understand this difference in catalytic selectivity for production of $\mathrm{N}_{2} \mathrm{O}$ on the two surfaces, structural models of $\mathrm{Rh}_{1} \mathrm{Co}_{3} / \mathrm{CoO}$ and $\mathrm{Rh}-\mathrm{Co}$ bimetallic nanoparticle/CoO (Supplementary Fig. 9) were built. The calculated adsorption energies of $\mathrm{N}_{2} \mathrm{O}$ for $\mathrm{Rh}_{1} \mathrm{Co}_{3} / \mathrm{CoO}$ and $\mathrm{Rh}-\mathrm{Co}$ bimetallic nanoparticles/CoO are -1.56 and $-0.85 \mathrm{eV}$, respectively. $\mathrm{N}_{2} \mathrm{O}$ is the by-product of the reduction of $\mathrm{NO}$ with $\mathrm{CO}$; it is also the intermediate for production of $\mathrm{N}_{2}$ (step 5 in Table 2). A stronger binding of $\mathrm{N}_{2} \mathrm{O}$ prevents it from molecular desorption. Thus, the selectivity for the production of $\mathrm{N}_{2} \mathrm{O}$ on $\mathrm{Rh}_{1} \mathrm{Co}_{3} / \mathrm{CoO}$ is low since the adsorption of $\mathrm{N}_{2} \mathrm{O}$ on $\mathrm{Rh}_{1} \mathrm{Co}_{3} / \mathrm{CoO}$ is stronger than that on $\mathrm{Rh}-\mathrm{Co}$ bimetallic nanoparticle/CoO. In addition, as the activation barrier for dissociating $\mathrm{N}_{2} \mathrm{O}$ to $\mathrm{N}_{2}$ and 
$\mathrm{O}$ on $\mathrm{Rh}_{1} \mathrm{Co}_{3} / \mathrm{CoO}$ is only $0.21 \mathrm{eV}$ (TS-2 in Fig. 7), $\mathrm{N}_{2} \mathrm{O}$ can readily dissociate to $\mathrm{N}_{2}$ on $\mathrm{Rh}_{1} \mathrm{Co}_{3} / \mathrm{CoO}$ at a relatively low temperature. Overall, the stronger binding of $\mathrm{N}_{2} \mathrm{O}$ on $\mathrm{Rh}_{1} \mathrm{Co}_{3}$ site and the rather low activation barrier for dissociation of the intermediate $\mathrm{N}_{2} \mathrm{O}$ to $\mathrm{N}_{2}$ on $\mathrm{Rh}_{1} \mathrm{Co}_{3} / \mathrm{CoO}$, make the reduction of $\mathrm{NO}$ to $\mathrm{N}_{2}$ with a high selectivity at a relatively low temperature in contrast to $\mathrm{Rh}-\mathrm{Co}$ bimetallic nanoparticles/CoO.

As described in literature ${ }^{25}$, the test temperature of engine of a gasoline vehicle is $1,100^{\circ} \mathrm{F}\left(593^{\circ} \mathrm{C}\right)$, stability tests by measurements of conversion and selectivity of the catalyst, $\mathrm{Rh}_{1} \mathrm{Co}_{3} / \mathrm{CoO}$ were performed. Concerning the real hydrothermal conditions in a three-way catalytic reactor, water vapour was also introduced to the reactor to simulate the exhaust of gasoline engines. As shown in literature ${ }^{26}$, typically the composition of water vapour is 20 times of nitric oxide and carbon monoxide. Thus, stability of $10 \mathrm{mg}$ catalyst was tested in a mixture of $12 \mathrm{ml} \mathrm{min}^{-1} \mathrm{NO}, 12 \mathrm{mlmin}^{-1} \mathrm{CO}, 68 \mathrm{ml} \mathrm{min}^{-1} \mathrm{Ar}$ and $\mathrm{H}_{2} \mathrm{O}$ vapour generated from $0.18 \mathrm{ml} \mathrm{min}^{-1}$ water were mixed and then introduced to a fixed-bed flow reactor. The molar ratio of NO:CO: $\mathrm{H}_{2} \mathrm{O}$ is $1: 1: 20$. The conversion and selectivity of this catalyst remained nearly constant within $168 \mathrm{~h}$.

These studies suggest that the isolation of bimetallic sites on non-metallic supports is a promising approach for developing catalysts, since such centres exhibit cationic states and offer the fewest binding configurations for reactant molecules-distinctly different from bimetallic nanoparticles.

\section{Methods}

Preparation of isolated $\mathbf{R} \mathbf{h}_{\mathbf{1}} \mathrm{Co}_{3}$ sites on cobalt oxide. $\mathrm{Co}_{3} \mathrm{O}_{4}$ nanorods were synthesized with a modified wet chemistry method in literature ${ }^{27}$. To synthesize a catalyst of singly dispersed $\mathrm{Rh}_{1} \mathrm{Co}_{3}$ sites, $\mathrm{Co}_{3} \mathrm{O}_{4}$ nanorods were synthesized with a modified wet chemistry method and a following calcination at high temperature 27,28 . Then, species of rhodium precursor were introduced on the crystallized $\mathrm{Co}_{3} \mathrm{O}_{4}$ nanorods through a deposition-precipitation with a mass ratio of $\mathrm{Rh}$ to $\mathrm{Co}_{3} \mathrm{O}_{4}$ of $0.25 \mathrm{wt} \%$.

$\mathrm{Rh}\left(\mathrm{NO}_{3}\right)_{3}$ (Sigma-Aldrich, $\sim 36 \% \mathrm{Rh}$ basis; $0.28 \mathrm{~g}$ ) was dissolved in water via a $50 \mathrm{ml}$ volumetric flask. $\mathrm{Co}_{3} \mathrm{O}_{4}$ nanorods $(0.80 \mathrm{~g})$ was dispersed in $50.0 \mathrm{~g}$ deionized water with strong agitation to make a homogeneous black suspension. The prepared $\mathrm{Rh}\left(\mathrm{NO}_{3}\right)_{3}$ aqueous solution was added by micropipette to the suspension of dispersed $\mathrm{Co}_{3} \mathrm{O}_{4}$ nanorods. Vigorous stirring for $1 \mathrm{~h}$ is necessary to make sure a homogeneous distribution and preliminary natural adsorption of $\mathrm{Rh}^{3+}$ on the surface of $\mathrm{Co}_{3} \mathrm{O}_{4}$ nanorods. The $\mathrm{pH}$ was then gradually adjusted to 9.0 by ammonium hydroxide solution monitored with a $\mathrm{pH}$ meter. After that, the solution was stirred vigorously for another $12 \mathrm{~h}$ to reach an equilibrium for a thorough, homogeneous adsorption of $\mathrm{Rh}^{3+}$ ions and followed by washing with deionized water and centrifuged. The catalyst precursor was dried in vacuum at $70{ }^{\circ} \mathrm{C}$ for at least $12 \mathrm{~h}$. Then it was oxidized and reduced at an appropriate temperature so that the singly dispersed bimetallic site $\mathrm{Rh}_{1} \mathrm{Co}_{3}$ can be prepared.

Synthesis of Rh-Co bimetallic nanoparticles supported on $\mathrm{CoO}$ and $\mathrm{Rh}-\mathrm{Co}$ alloy nanoparticles $/ \mathrm{SiO}_{2}$ (Rh: $5 \mathrm{wt} \%$ ) was achieved by aqueous impregnation of $\mathrm{Rh}$ and Co precursors to $\mathrm{SiO}_{2} \mathrm{NPs}$ or $\mathrm{Co}_{3} \mathrm{O}_{4}$ nanorods. $\mathrm{Rh}\left(\mathrm{NO}_{3}\right)_{3} \cdot x \mathrm{H}_{2} \mathrm{O}$ (SigmaAldrich, $\sim 36 \% \mathrm{Rh}$ basis) and $\mathrm{Co}\left(\mathrm{NO}_{3}\right)_{3} \cdot 6 \mathrm{H}_{2} \mathrm{O}$ (Sigma-Aldrich, $\geq 98 \%$ ) were used as precursors of $\mathrm{Rh}$ and Co, respectively. The total weight per cent of $\mathrm{Rh}$ and Co is $5 \mathrm{wt} \%$ while keeping the atomic ratios of the loaded $\mathrm{Rh}$ and Co identical.

$\mathrm{Rh}\left(\mathrm{NO}_{3}\right)_{3} \cdot x \mathrm{H}_{2} \mathrm{O}$ and $\mathrm{Co}\left(\mathrm{NO}_{3}\right)_{2} \cdot 6 \mathrm{H}_{2} \mathrm{O}$ were dissolved in deionized water to make a clear solution. $\mathrm{SiO}_{2}(0.5 \mathrm{~g})$ or $\mathrm{Co}_{3} \mathrm{O}_{4}$ nanorods $(0.5 \mathrm{~g})$ were immersed into the solution. The water was gradually evaporated at $60^{\circ} \mathrm{C}$ with vigorous stirring and the catalyst was then dried in vacuum at $60^{\circ} \mathrm{C}$ for $12 \mathrm{~h}$, followed by calcination in $5 \% \mathrm{O}_{2}$ at $150^{\circ} \mathrm{C}$ for $3 \mathrm{~h}$. Before catalytic measurement, the catalyst was pretreated at $300{ }^{\circ} \mathrm{C}$ in $5 \% \mathrm{H}_{2}$

$\mathrm{Rh}_{1} \mathrm{O}_{n} / \mathrm{CoO}$ was synthesized by introduction of $\mathrm{Rh}$ cations to well-prepared $\mathrm{CoO}$ by deposition-precipitation with a following annealing in $\mathrm{N}_{2}$ and then a reduction at $200{ }^{\circ} \mathrm{C}$ in $5 \% \mathrm{H}_{2}$ for $1 \mathrm{~h}$.

\section{In situ studies using ambient pressure X-ray photoelectron spectroscopy.}

In situ studies of surface chemistry of these catalysts were performed on the ambient pressure XPS using monochromated $\mathrm{Al} \mathrm{K} \alpha$ in the Tao group ${ }^{11,29,30}$. The binding energy of catalyst samples were calibrated to $\mathrm{Au} 4 f_{7 / 2}$ at $84.0 \mathrm{eV}$ and $\mathrm{Ag}$ $3 d_{5 / 2}$ at $368.3 \mathrm{eV}$ (ref. 11). In the AP-XPS studies, one or more reactant gases were introduced into a reactor. A sample is inserted and placed at the cross point of Rowland cycle of the monochromator and trajectory line of photoelectrons in lens of differentially pumped energy analyser. A distance between sample surface and the aperture of pre-lens of the differential pumping stage remains at $\sim 0.5 \mathrm{~mm}$, which is shorter than the mean free paths of photoelectrons travelling in a gaseous environment of 5 Torr.

Measurements of catalytic performance for reduction of NO with $\mathrm{CO}$. Reduction of NO with CO on catalysts is performed in a fixed-bed flow reactor. Gas computations and flow rates were marked in captions of figures. Details of catalytic measurement using our fixed-bed flow reactor can be found in our previous publications ${ }^{9,10}$

In situ studies using XANES and EXAFS. In situ X-ray absorption spectroscopy (XANES) measurements were performed at the beamline X18B at the National Synchrotron Light Source, Brookhaven National Laboratory. The samples were made by pressing the powders into circular pellets using hydraulic press and transferred onto a sample holder of a Nashner-Adler in situ cell ${ }^{31}$.

The data in the XANES region of the absorption coefficient were analysed by applying the same procedure for pre-edge line fitting, post-edge curve fitting and edge-step normalization to all the data. The XANES and extended X-ray absorption fine structure (EXAFS) data processing and analysis were performed using the IFEFFIT package ${ }^{32}$. The EXAFS data modelling and analysis were performed using standard procedures ${ }^{32-36}$.

Computational methods. The calculations were performed with the Vienna Ab-initio Simulation Package (VASP version 5.2). Both (011) and (001) surfaces of cobalt monoxide were represented by a periodic slab model constructed using bulk cell dimensions: $a=b=c=4.2667 \AA$ (ref. 37). Only calculation results of (011) surface were described in the main text. Since $\mathrm{CoO}$ is antiferromagnetic and has atomic moment on cobalt atoms, the primitive cubic unit cell of $\mathrm{CoO}$ was used to build the surface slab, which was previously proved to be the most energetically stable configuration for $\mathrm{CoO}^{38}$. The repeated slabs were separated from their neighbouring images by a $12 \AA$-width vacuum in the direction perpendicular to the surface. Considering the usually very large relaxations of the CoO surfaces, a slab containing five layers of 60 atoms was chosen. The three top-layer slabs of the surface were allowed to relax while the other layers beneath the surface were frozen during the geometry optimization (Supplementary Fig. 10).

The core and valence electrons were represented by the projector-augmented wave method and plane-wave basis functions with a kinetic energy cut-off of $400 \mathrm{eV}$. Inasmuch as $\mathrm{Rh}$ has non-negligible relativistic effects, the mass-velocity and Darwin relativistic effects were included through the projector-augmented wave potentials. The generalized gradient approximation with the PerdewBurke-Ernzerhof exchange-correlation functional was used in the calculations. A Monkhorst-Pack grid of size of $2 \times 2 \times 1$ was used to sample the surface Brillouin zone. Ground-state atomic geometries were obtained by minimizing the forces on the atoms to $<0.02 \mathrm{eV}^{-1}$. Because of the strong $d$-electron correlation effects for $\mathrm{Co}$, the calculations were carried out with the DFT $+\mathrm{U}$ method. The parameters were set at $U=4 \mathrm{eV}$ and $J=1 \mathrm{eV}$ according to previous reports ${ }^{39}$ and our investigation (Supplementary Tables 5,6 ). The transition states were obtained by relaxing the force $<0.02 \mathrm{eV}^{-1}$ by using the dimer method 40

\section{References}

1. Somorjai, G. A. L. Y. M. Introduction to Surface Chemistry and Catalysis. 2nd Edition (Wiley, 2010).

2. Ertl, G., Knözinger, H., Schuth, F. \& Weitkamp, J. Handbook of Heterogeneous Catalysis (Wiley-VCH, 2008).

3. Guo, X. et al. Direct, nonoxidative conversion of methane to ethylene, aromatics, and hydrogen. Science 344, 616-619 (2014).

4. Chen, M. S., Kumar, D., Yi, C. W. \& Goodman, D. W. The promotional effect of gold in catalysis by palladium-gold. Science 310, 291-293 (2005).

5. Kyriakou, G. et al. Isolated metal atom geometries as a strategy for selective heterogeneous hydrogenations. Science 335, 1209-1212 (2012).

6. Zhu, Y. et al. Catalytic conversion of carbon dioxide to methane on ruthenium cobalt bimetallic nanocatalysts and correlation between surface chemistry of catalysts under reaction conditions and catalytic performances. ACS Catal. 2, 2403-2408 (2012).

7. Chen, J., Wu, X. F. \& Selloni, A. Electronic structure and bonding properties of cobalt oxide in the spinel structure. Phys. Rev. B 83, 245204 (2011).

8. Xie, X. W., Li, Y., Liu, Z. Q., Haruta, M. \& Shen, W. J. Low-temperature oxidation of $\mathrm{CO}$ catalysed by $\mathrm{Co}_{3} \mathrm{O}_{4}$ nanorods. Nature 458, 746-749 (2009).

9. Zhang, S. et al. Restructuring transition metal oxide nanorods for $100 \%$ selectivity in reduction of nitric oxide with carbon monoxide. Nano Lett. 13, 3310-3314 (2013).

10. Zhang, S. et al. WGS catalysis and in situ studies of $\mathrm{CoO}_{1-\mathrm{x}}, \mathrm{PtCon} / \mathrm{Co}_{3} \mathrm{O}_{4}$, and $\mathrm{Pt}_{\mathrm{m}} \mathrm{Co}_{\mathrm{m}} / \mathrm{CoO}_{1-\mathrm{x}}$ nanorod catalysts. J. Am. Chem. Soc. 135, 8283-8293 (2013)

11. Tao, F. Design of an in-house ambient pressure AP-XPS using a bench-top $\mathrm{X}$-ray source and the surface chemistry of ceria under reaction conditions. Chem. Commun. 48, 3812-3814 (2012).

12. Moulder, J. F. S., Sobol, W. F. \& Bomben, P. E. K. D. Handbook of X-ray Photoelectron Spectroscopy (Perkin-Elmer Corporation, 1992). 
13. Yang, J. C., Small, M. W., Grieshaber, R. V. \& Nuzzo, R. G. Recent developments and applications of electron microscopy to heterogeneous catalysis. Chem. Soc. Rev. 41, 8179-8194 (2012).

14. Chuang, T. J., Brundle, C. R. \& Rice, D. W. Interpretation of X-ray photoemission spectra of cobalt oxides and cobalt oxide surfaces. Surf. Sci. 59, 413-429 (1976).

15. Petitto, S. C., Marsh, E. M., Carson, G. A. \& Langell, M. A. Cobalt oxide surface chemistry: the interaction of $\mathrm{CoO}(100), \mathrm{Co}_{3} \mathrm{O}_{4}(110)$ and $\mathrm{Co}_{3} \mathrm{O}_{4}(111)$ with oxygen and water. J. Mol. Catal. A Chem. 281, 49-58 (2008).

16. Renzas, J. R., Zhang, Y. W., Huang, W. Y. \& Somorjai, G. A. Rhodium nanoparticle shape dependence in the reduction of NO by CO. Catal. Lett. 132, 317-322 (2009).

17. Gao, F., Wang, Y. \& Goodman, D. W. CO/NO and $\mathrm{CO} / \mathrm{NO} / \mathrm{O}_{-2}$ reactions over a Au-Pd single crystal catalyst. J. Catal. 268, 115-121 (2009).

18. Lambrou, P. S. \& Efstathiou, A. M. The effects of Fe on the oxygen storage and release properties of model $\mathrm{Pd}-\mathrm{Rh} / \mathrm{CeO}_{2}-\mathrm{Al}_{2} \mathrm{O}_{3}$ three-way catalyst. J. Catal. 240, 182-193 (2006).

19. Maillet, T., Barbier-Jr, J., Gelin, P., Praliaud, H. \& Duprez, D. Effects of pretreatments on the surface composition of alumina-supported $\mathrm{Pd}-\mathrm{Rh}$ catalysts. J. Catal. 202, 367-378 (2001).

20. Rider, K. B., Hwang, K. S., Salmeron, M. \& Somorjai, G. A. High-pressure (1 Torr) scanning tunneling microscopy (STM) study of the coadsorption and exchange of CO and NO on the Rh(111) crystal face. J. Am. Chem. Soc. 124, 5588-5593 (2002)

21. Herman, G. S., Peden, C. H. F., Schmieg, S. J. \& Belton, D. N. A comparison of the NO-CO reaction over $\mathrm{Rh}(100), \mathrm{Rh}(110)$ and $\mathrm{Rh}(111)$. Catal. Lett. 62, 131-138 (1999).

22. Yang, X.-F. et al. Single-atom catalysts: a new frontier in heterogeneous catalysis. Acc. Chem. Res. 46, 1740-1748 (2013).

23. Qiao, B. et al. Single-atom catalysis of $\mathrm{CO}$ oxidation using $\mathrm{Pt}_{-1} / \mathrm{FeO}_{\mathrm{x}}$. Nat. Chem. 3, 634-641 (2011).

24. Lin, J. et al. Remarkable performance of $\mathrm{Ir}_{1} / \mathrm{FeO}_{\mathrm{x}}$ single-atom catalyst in water gas shift reaction. J. Am. Chem. Soc. 135, 15314-15317 (2013).

25. Harrison, R. T. Catalytic converter exhaust system temperature tests. (U.S. Department of Agriculture, Equipment Development Center (1977).

26. Srinivasan, A. \& Depcik, C. Review of chemical reactions in the NO reduction by CO on rhodium/alumina catalysts. Catal. Rev. Sci. Eng. 52, 462-493 (2010).

27. Xie, X. W. et al. Synthesis of nanorod-shaped cobalt hydroxycarbonate and oxide with the mediation of ethylene glycol. J. Phys. Chem. C 114, 2116-2123 (2010).

28. Wang, L. et al. Catalysis and In Situ studies of $\mathrm{Rh}_{-1} / \mathrm{Co}_{3} \mathrm{O}_{4}$ nanorods in reduction of NO with $\mathrm{H}_{-2}$. ACS Catal. 3, 1011-1019 (2013).

29. Shan, J. J. et al. Catalytic performance and in situ surface chemistry of pure alpha- $\mathrm{MnO}_{2}$ nanorods in selective reduction of $\mathrm{NO}$ and $\mathrm{N}_{2} \mathrm{O}$ with CO. J. Phys. Chem. C 117, 8329-8335 (2013).

30. Tao, F. et al. Understanding complete oxidation of methane on spinel oxides at molecular level. Nat. Commun. 6, 7798 doi:10.1038/ncomms8798 (2015).

31. Nashner, M. S., Frenkel, A. I., Adler, D. L., Shapley, J. R. \& Nuzzo, R. G. Structural characterization of carbon-supported platinum-ruthenium nanoparticles from the molecular cluster precursor $\mathrm{PtRu}_{5} \mathrm{C}(\mathrm{CO})_{(16)} . \mathrm{J} . \mathrm{Am}$. Chem. Soc. 119, 7760-7771 (1997).

32. Newville, M. IFEFFIT: interactive XAFS analysis and FEFF fitting. J. Synchrotron Rad. 8, 322 (2001).

33. Frenkel, A. I., Hills, C. W. \& Nuzzo, R. G. A view from the inside: complexity in the atomic scale ordering of supported metal nanoparticles. J. Phys. Chem. B 105, 12689-12703 (2001).

34. Frenkel, A. Solving the 3D structure of metal nanoparticles. Z Kristallogr. 222, 605-611 (2007).
35. Frenkel, A. I. Applications of extended X-ray absorption fine-structure spectroscopy to studies of bimetallic nanoparticle catalysts. Chem. Soc. Rev. 41, 8163-8178 (2012).

36. Frenkel, A. I., Yevick, A., Cooper, C. \& Vasic, R. Modeling the structure and composition of nanoparticles by extended X-ray absorption fine-structure spectroscopy. Annu. Rev. Anal. Chem. 4, 23-39 (2011).

37. Henrich, V. E. \& Cox, P. A. The Surface Science of Metal Oxides (Cambridge University Press, 1996).

38. Wyckoff, R. W. G. Crystal Structure 2nd edition (Interscience Publishers, 1965)

39. Wang, L., Maxisch, T. \& Ceder, G. Oxidation energies of transition metal oxides within the GGA + U framework. Phys. Rev. B 73, 195107 (2006).

40. Henkelman, G. \& Jonsson, H. A dimer method for finding saddle points on high dimensional potential surfaces using only first derivatives. J. Chem. Phys. 111, 7010-7022 (1999).

\section{Acknowledgements}

This work is mainly supported by the Chemical Catalysis Program of Division of Chemistry, National Science Foundation (NSF Career Award) No. 1462121. F.T. acknowledged the support from Miller Scholar Award program. The theoretical work is supported by the China Key Basic Research Special Foundations (2013CB834603 and 2011CB932401) and the GZNC startup package. The calculations were performed at the Tsinghua National Laboratory for Information Science and Technology and the Guizhou Provincial High-Performance Computing Center of Condensed Materials and Molecular Simulation. AIF an AP were supported by the US Department of Energy, Office of Basic Energy Sciences under Grant No. DE-FG02-03ER15476. We acknowledge the facilities support provided at the National Synchrotron Light Source at the Brookhaven National Laboratory (US Department of Energy, Office of Basic Energy Sciences, Contract No. DE-SC0012704) and the Synchrotron Catalysis Consortium (US Department of Energy, Office of Basic Energy Sciences, Grant No. DE-SC0012335). J.L. (Liu) is supported by the startup fund of the College of Liberal Arts and Sciences of Arizona State University. Part of the electron microscopy data was obtained at the John M Cowley Center for High Resolution Electron Microscopy at Arizona State University.

\section{Author contributions}

F.T. launched the project of catalysis on singly dispersed bimetallic sites of his NSF Career Award, designed the synthesis, catalysis and in situ characterizations of singly dispersed bimetallic sites, analysed the experimental results and wrote this paper. J.L. designed the theoretical studies and wrote the computational part. S.Z. performed majority of the experiments. L.N. interpretation of the experimental results and participated in the writing. J.-X.L. performed the theoretical calculations. J.L (Liu) performed HAADF-STEM. S.Z and A.P. performed the EXAFS experiments. A.I.F. analysed the EXAFS data. J.S. and W.H. collected some of the AP-XPS data.

\section{Additional information}

Supplementary Information accompanies this paper at http://www.nature.com/ naturecommunications

Competing financial interests: The authors declare no competing financial interests.

Reprints and permission information is available online at http://npg.nature.com/ reprintsandpermissions/

How to cite this article: Zhang, S. et al. Catalysis on singly dispersed bimetallic sites. Nat. Commun. 6:7938 doi: 10.1038/ncomms8938 (2015). 